\title{
Photoinactivation of ESKAPE pathogens: overview of novel therapeutic strategy
}

\author{
Joanna Nakonieczna ${ }^{\ddagger}{ }^{1}$, Agata Wozniak ${ }^{1}$, Michal Pieranski $^{1}$, Aleksandra \\ Rapacka-Zdonczyk ${ }^{1}$, Patrycja Ogonowska ${ }^{1}$ \& Mariusz Grinholc*, M $^{*}$ \\ ${ }^{1}$ Laboratory of Molecular Diagnostics, Department of Biotechnology, Intercollegiate Faculty of Biotechnology University of Gdansk \\ \& Medical University of Gdansk, Abrahama 58, 80-307 Gdansk, Poland \\ *Author for correspondence: Tel../Fax: +48 585236 327; mariusz.grinholc@biotech.ug.edu.p \\ ${ }^{\ddagger}$ Authors contributed equally
}

\begin{abstract}
The emergence of antimicrobial drug resistance requires development of alternative therapeutic options. Multidrug-resistant strains of Enterococcus spp., Staphylococcus aureus, Klebsiella pneumoniae, Acinetobacter baumanii, Pseudomonas aeruginosa and Enterobacter spp. are still the most commonly identified antimicrobial-resistant pathogens. These microorganisms are part of the so-called 'ESKAPE' pathogens to emphasize that they currently cause the majority of hospital acquired infections and effectively 'escape' the effects of antibacterial drugs. Thus, alternative, safer and more efficient antimicrobial strategies are urgently needed, especially against 'ESKAPE' superbugs. Antimicrobial photodynamic inactivation is a therapeutic option used in the treatment of infectious diseases. It is based on a combination of a photosensitizer, light and oxygen to remove highly metabolically active cells.
\end{abstract}

First draft submitted: 14 July 2018; Accepted for publication: 6 December 2018; Published online: 22 March 2019

Keywords: acinetobacter $\bullet$ antimicrobial $\bullet$ enterobacter $\bullet$ Enterococcus $\bullet$ Klebsiella $\bullet$ photodynamic inactivation $\bullet$ photoinactivation • photosensitizer $\bullet$ Pseudomonas $\bullet$ Staphylococcus

Although routinely used antimicrobials have been considered miraculous drugs for the past 80 years, the emergence of antimicrobial drug resistance requires the development of alternative therapeutic options. The drug resistance of microbes is a serious challenge for modern medicine. A dynamic emergence of microorganisms with high drug resistance, in particular resistance to many antibiotics, is observed worldwide. Therefore, it seems necessary to search for complex solutions based on antimicrobial compounds or methods that interact with many cellular targets. Multidrug-resistant (MDR) strains of Enterococcus spp., Staphylococcus aureus, Klebsiella pneumoniae, Acinetobacter baumanii, Pseudomonas aeruginosa and Enterobacter spp. are still the most commonly identified antimicrobial-resistant pathogens. These microorganisms are part of the so-called 'ESKAPE' pathogens to point out that they are the cause of most cases of hospital infections and express mechanisms that allow them to effectively 'escape' from the action of antibacterial drugs [1]. CDC define few major antimicrobial drugdevelopment needs in case of ESKAPE pathogens: methicillin-resistant $S$. aureus (MRSA), vancomycin-resistant $E$. faecium (VRE), fluoroquinolone-resistant $P$. aeruginosa, extended-spectrum $\beta$-lactamases (ESBL)-producing and carbapenem-resistant Enterobacteriaceae and carbapenem-resistant Acinetobacter [2]. Worth noticing that more people now die of MRSA infection than of HIV/AIDS and tuberculosis combined [3]. The emergence of bacterial resistance to many antibiotics poses a serious threat to public health. We have less and less resource of efficient antimicrobial drugs, and in some cases there are no effective treatment options. For more precise control of the spread and accumulation of drug resistance mechanisms among microbes, a clear definition determining the level of drug resistance within microorganisms has been introduced. The proposed classification distinguishes MDR strains, strains with extended drug resistance (extensively drug-resistant) and strains resistant to all currently available antimicrobial drugs (pandrug resistant). This terminology was introduced by the european centre for disease control and prevention (ECDC) to standardize drug resistance profiles of S. aureus, Enterococcus spp., Enterobacteriaceae, $P$. aeruginosa and Acinetobacter spp. It is extremely important to be aware that clinicians and scientists are already facing the emergence of panantibiotic-resistant infections. Extremely limited therapeutic options for 
these pathogens force clinicians to employ previously discarded drugs with significant toxicity and lack of data concerning dosage regimen or duration of therapy [4]. In addition, we are witnessing both the growing number of elderly patients as well as patients undergoing serious treatment procedures like surgery, transplantation and chemotherapy, which would finally lead to an increased number of immunocompromised individuals at risk of these infections [5]. Thus, alternative safer and more efficient antimicrobial strategies are urgently needed, especially against 'ESKAPE' superbugs.

Antimicrobial photodynamic inactivation (aPDI) is a therapeutic option used in the treatment of infectious diseases. It is based on a combination of a photosensitizer (PS), light and oxygen to remove highly metabolically active cells, in other words, fungi, viruses or bacteria. Triplet-excited PS is a basic element of the aPDI activity, leading to the formation of singlet oxygen and/or radicals. The action of these reactive oxygen species (ROS) leads to damage to numerous biological molecules and, consequently, to the death of the desired cells [6]. In comparison with other methods of treatment, aPDI has several advantages. Photoactivation allows the local treatment, which reduces the side effects of photodynamic therapy. In addition, aPDI has several cellular targets and therefore it is not biased by development of resistance to the treatment. However, despite such advantages, and increasing knowledge about the effectiveness of photodynamic therapy, it is clear that clinical application of aPDI is still not widespread. Many researchers have focused on finding new or modifying existing PSs in order to maximize the quantum yield of singlet oxygen in the in vitro tests, simultaneously studying molecular aspects occurring in microbial cells and the factors affecting different susceptibility of microbes to the photoinactivation. Notably, it is still unclear which are the most important and essential biological targets in photodynamic reaction for achieving effective eradication of microorganisms and which genetic or phenotypic features of microorganisms determine their response to the photoinactivation. In our opinion, reviewing and presenting the successful applications of aPDI against ESKAPE infections is indispensable for the dissemination of its effective clinical use. Starting from the biological effects of photodynamic inactivation, we will discuss studies that exemplify the most pronounced bactericidal effectiveness against ESKAPE pathogens in in vitro (both planktonic and biofilm cultures) as well as in vivo and clinical trials. We believe that this analysis will help with understanding that developed improved aPDI protocols are promising alternative for infectious diseases treatment.

The main motivation for writing this review is to present reliable studies that could convince medical chemists, microbiologists and clinicians of unquestionable features and the potential of aPDI for the treatment of infectious diseases. In addition, we will also indicate several open questions and challenges, hoping that they will encourage further research in this area.

\section{aPDI against ESKAPE pathogens}

Below, the description and discussion of most recent and pronounced studies concerning aPDI efficacy against ESKAPE pathogens is provided. More detailed description of existing findings is presented in appropriate tables (for planktonic cultures, see Table 1; for biofilm-related studies refer to Table 2 and for in vivo/ ex vivo studies follow Table 3).

\section{Enterococcus spp.}

Enterococcus is a genus of a Gram-positive, facultative anaerobic, catalase-negative and nonspore-forming bacteria. The main pathogens associated with a wide range of clinical infections are Enterococcus faecalis and Enterococcus faecium. These bacteria can cause wound infections, bacteremia, urinary tract infection (UTI), endodontic infections, endocarditis, intra-abdominal infections and neonatal sepsis $[7,8]$. Today, an increasing rate of resistance to many groups of antibiotics has been observed, especially to drugs of last resort. Within the Enterococcus genus are VRE. Diseases caused by VRE strains could be effectively treated with very limited antimicrobial therapies [7]. Moreover, numerous study reveal that $E$. faecalis plays an important role in endodontic infections and it can be found in the root canal system [9]. This species in the form of biofilm is considered as one of the most resistant species in oral cavity, due to the resistance to conventional antimicrobial agents: chlorhexidine or sodium hypochlorite [10]. Therefore, when routinely used therapeutic options are insufficient, scientists are aimed at research on alternative or complementary treatments. aPDI is a promising option leading to Enterococcus spp. eradication. Numerous studies were performed in this field both in case of in vitro and ex vivo (planktonic and biofilm) cultures. In 2015, Liu et al. investigated the effectiveness of two compounds: 5-aminolevulinic acid (5-ALA) and its derivative 5-ALA methyl ester (MAL) against two vancomycin-resistant $E$. faecalis strains employing LED lamp emitting red 
Table 1. Antimicrobial photodynamic inactivation of ESKAPE pathogens in planktonic cultures.

\begin{tabular}{|c|c|c|c|c|c|c|}
\hline Photosensitizer & Light source & $\begin{array}{l}\text { Wavelength } \\
(\mathrm{nm})\end{array}$ & $\begin{array}{l}\text { Irradiance } \\
\left(\mathrm{mW} / \mathrm{cm}^{2}\right)\end{array}$ & Fluence $\left(\mathrm{J} / \mathrm{cm}^{2}\right)$ & Max. reduction $\left(\log _{10}\right)$ & Refs. \\
\hline \multicolumn{7}{|l|}{ Enterococcus faecalis } \\
\hline \multicolumn{7}{|l|}{ Porphyrins: } \\
\hline - 5-ALA/MAL & LED & 633 & 80 & 288 & $5.37 / 5.02$ & [11] \\
\hline \multicolumn{7}{|l|}{ Phenothiazines: } \\
\hline$-M B$ & LED & 660 & 153 & 90 & 9.98 & [87] \\
\hline - EtNBS + derivatives & Noncoherent & 635 & 50 & 10 & $5-7$ & [23] \\
\hline Xanthenes: & Dental QTH & $380-500$ & 450 & 108 & 7.3 & [88] \\
\hline \multicolumn{7}{|l|}{$-\mathrm{RB}$} \\
\hline \multicolumn{7}{|l|}{ Others: } \\
\hline$-\mathrm{Ce} 6$ & LED & 660 & 153 & 60 & 10.20 & [87] \\
\hline - CUR & LED/Dental QTH & $450 / 380-500$ & $151 / 450$ & $25 / 108$ & $10.32 / 7.65$ & {$[87,88]$} \\
\hline - Erythrosine & LED & $440-480$ & 1200 & 96 & 9.55 & [12] \\
\hline$-I C G$ & NIR diode laser & 808 & 2.38 & 143 & 5.1 & [89] \\
\hline - Eosin-Y & Dental QTH & $380-500$ & 450 & 108 & 4.9 & [88] \\
\hline - HYP & LED & 590 & 80 & 14.4 & 6.5 & [90] \\
\hline - Bacteriochlorins & NIR & $700-850$ & 100 & 10 & $>6$ & [41] \\
\hline \multicolumn{7}{|l|}{ Staphylococcus aureus } \\
\hline aBLT & LED & $405 / 400$ & $21 / 60$ & $306 / 54-108$ & $4 />6$ & {$[91,42]$} \\
\hline \multicolumn{7}{|l|}{ Porphyrin: } \\
\hline - 5-ALA & LED & 410 & 50 & 164.5 & 5 & [29] \\
\hline - PplX & $\begin{array}{l}\text { Q. Light PDT } \\
\text { lamp }\end{array}$ & $620-780$ & 102 & 50 & $\sim 2-4.51$ & [92] \\
\hline - PPArg $_{2}$ & LED & 627 & 23.4 & 20 & $4.46-5.53$ & [93] \\
\hline - Tetra-Py ${ }^{+}-\mathrm{Me}$ & $\begin{array}{l}\text { Artificial white } \\
\text { light }\end{array}$ & $380-700$ & 4 & 14.4 & $>5$ & [94] \\
\hline \multicolumn{7}{|l|}{ Phenothiazines: } \\
\hline - EtNBS + derivatives & Noncoherent & 635 & 50 & 10 & $\sim 3-6$ & [23] \\
\hline- TBO & Diode laser & 633 & 32 & 6 & 5.83 & [95] \\
\hline \multicolumn{7}{|l|}{ Phthalocyanines: } \\
\hline - RLP068/Cl & Lumacare lamp & 690 & 100 & 10 & $\sim 8$ & [96] \\
\hline - Monosubstituted ZnPC/ZnPC & LED & $610 / 627$ & $40 / 23.4$ & 48 & $4 / 3.49-5.77$ & {$[93,97]$} \\
\hline Xanthenes: & LED & 520 & 23.4 & 20 & $3.37-5.47$ & [93] \\
\hline \multicolumn{7}{|l|}{$-\mathrm{RB}$} \\
\hline \multicolumn{7}{|l|}{ Fullerenes: } \\
\hline - Fulleropyrrolidine & $\begin{array}{l}\text { Q. Light PDT } \\
\text { lamp }\end{array}$ & $385-780$ & 267 & 160 & $3.5->6$ & [28] \\
\hline \multicolumn{7}{|l|}{ Others: } \\
\hline - DIMPy - BODIPY/BODIPYs & Noncoherent & $\begin{array}{l}400-700 / 350- \\
800\end{array}$ & $65 / 70$ & $118 / 21$ & $5-6 />5$ & {$[25,31]$} \\
\hline - CUR & LED & 455 & 22 & 37.5 & $6-9.8$ & [98] \\
\hline - HYP & LED & 602 & 14 & 8 & $>3$ & [99] \\
\hline - Imidazoacridinone derivative & $\begin{array}{l}\text { Q. Light PDT } \\
\text { lamp }\end{array}$ & $385-480$ & 100 & 100 & $3.2-5$ & [100] \\
\hline$-\mathrm{NR}, \mathrm{NRBr}$ & $\begin{array}{l}\text { Visible light } \\
\text { source }\end{array}$ & $385-780$ & $\sim 16.8$ & 30.2 & $\sim 3.7-\sim 5$ & [24] \\
\hline - Porphyrin-fullerene $C_{60}$ & $\begin{array}{l}\text { Visible light } \\
\text { source }\end{array}$ & $350-800$ & 90 & 162 & $>4.5$ & [101] \\
\hline $\begin{array}{l}\text { aBLT: Antimicrobial blue light treatr } \\
\text { Indocyanine green; KI: Potassium i } \\
\text { Monobrominated neutral red; PpIX } \\
\text { ortho; THL: Tungsten-halogen lamp }\end{array}$ & $\begin{array}{l}\text {; AlGalnP diode lase } \\
\text {; LC 16: C60 fullerer } \\
\text { toporphyrin IX; PPAr } \\
\text { A: Ultraviolet A; ZnF }\end{array}$ & $\begin{array}{l}\text { er: Aluminum galli } \\
\text { ne derivate; LED: } \\
\mathrm{rg}_{2} \text { : Protoporphyri } \\
\text { PC: Zinc phthalocy }\end{array}$ & $\begin{array}{l}\text { indium phosp } \\
\text { t-emitting dic } \\
\text { X diarginate; } P \\
\text { ine. }\end{array}$ & $\begin{array}{l}\text { iode laser; DL: Dioc } \\
\text { : No data; NMB: N } \\
\text { cosensitizer; QTH: C }\end{array}$ & $\begin{array}{l}\text { e laser; He-Ne laser: Heliun } \\
\text { ww methylene blue; NIR: Ne } \\
\text { uartz-tungsten-halogen; RB }\end{array}$ & $\begin{array}{l}\text { in; ICG: } \\
\text { d; NRBr: } \\
\text { ine blue }\end{array}$ \\
\hline
\end{tabular}


Table 1. Antimicrobial photodynamic inactivation of ESKAPE pathogens in planktonic cultures (cont.).

\begin{tabular}{|c|c|c|c|c|c|c|}
\hline Photosensitizer & Light source & $\begin{array}{l}\text { Wavelength } \\
(\mathrm{nm})\end{array}$ & $\begin{array}{l}\text { Irradiance } \\
\left(\mathrm{mW} / \mathrm{cm}^{2}\right)\end{array}$ & Fluence $\left(\mathrm{J} / \mathrm{cm}^{2}\right)$ & Max. reduction $\left(\log _{10}\right)$ & Refs. \\
\hline - Radachlorin ${ }^{\circledR}$ & Diode laser & 662 & 213 & $12 / 6$ & $6.28 / 6.1$ & {$[95,102]$} \\
\hline - Ru(II)-based PS & Noncoherent & $530 / 525$ & $98 / 50$ & $58.8 / 100$ & $6.7-8.3 / 6$ & {$[51,103]$} \\
\hline - Ru(II) complexes & $\begin{array}{l}\text { Dual- } \\
\text { wavelength } \\
\text { laser }\end{array}$ & $457 / 532$ & 40 & 24 & $\sim 5-\sim 8$ & [104] \\
\hline - Ryboflavin derivates & Noncoherent & $380-600$ & 50 & 1.5 & $6.5-6.6$ & [22] \\
\hline \multicolumn{7}{|l|}{ Klebsiella pneumoniae } \\
\hline \multicolumn{7}{|l|}{ Porphyrins: } \\
\hline - Porphyrin paper/PpIX+KI & \multicolumn{2}{|c|}{ Noncoherent/LED } & $65 / 50$ & $118 / 10$ & $4 />6$ & {$[33,105]$} \\
\hline - ALA/MAL & Noncoherent & $400-780$ & 100 & 360 & $3.17-3.68 / 4.3-4.8$ & [34] \\
\hline Phenothiazines: & Laser & 630 & 130 & 39 & 3 & [32] \\
\hline \multicolumn{7}{|l|}{ - TBO/NMB/Azure A } \\
\hline Phthalocyanines: & Visible light & ND & 20.5 & 45 & 4.3 & [35] \\
\hline \multicolumn{7}{|l|}{ - ZnTM2, 3PyPz } \\
\hline \multicolumn{7}{|l|}{ Others: } \\
\hline - DIMPy - BODIPY & Noncoherent & $400-700$ & 65 & 118 & $4-5$ & [31] \\
\hline - 2,3-Distyrylindole & Lumacare lamp & ND & - & - & - & [30] \\
\hline - Vitamin K & UVA & - & - & 30 & 5.8 & [36] \\
\hline \multicolumn{7}{|l|}{ Acinetobacter baumannii } \\
\hline aBLT & LED & $400 / 415$ & $60 / 19.5$ & $108 / 70.2$ & $7.06 />4$ & {$[42,106]$} \\
\hline \multicolumn{7}{|l|}{ Porphyrins: } \\
\hline - Tetra-Py+-Me & $\begin{array}{l}\text { White lamps } \\
\text { (OSRAM) }\end{array}$ & $380-700$ & 40 & 64.8 & 6 & [43] \\
\hline - $4 \mathrm{I}$ Conjugate & $\begin{array}{l}\text { Semiconductor } \\
\text { laser }\end{array}$ & 650 & - & 6 & $3.77-3.83$ & [44] \\
\hline \multicolumn{7}{|l|}{ Phenothiazines: } \\
\hline - EtNBS derivatives & Noncoherent & 635 & 50 & 10 & $5-7$ & [23] \\
\hline$-M B$ & - & 652 & 100 & 6 & $\sim 4$ & [107] \\
\hline Fullerenes: & Lumacare lamp & $400-700$ & 100 & 120 & 4 & [78] \\
\hline \multicolumn{7}{|l|}{$-\mathrm{LC} 16+\mathrm{KI}$} \\
\hline \multicolumn{7}{|l|}{ Other: } \\
\hline - Bacteriochlorins & NIR & $700-850$ & 100 & 10 & $5-6$ & [41] \\
\hline - Ryboflavin derivates & Noncoherent & $380-600$ & 50 & 9 & $>6$ & [22] \\
\hline - DIMPy-BODIPY & Noncoherent & $400-700$ & 65 & 118 & $4-6$ & [31] \\
\hline \multicolumn{7}{|l|}{ Pseudomonas aeruginosa } \\
\hline \multirow[t]{2}{*}{ aBLT: } & LED & $410 / 411$ & $60 / 15.7$ & $108 / 50$ & $6.55 / 7$ & {$[42,53]$} \\
\hline & LED & 415 & $20 / 19.5$ & $48 / 109.9$ & $3.54 / 7.64$ & {$[52,108]$} \\
\hline \multicolumn{7}{|l|}{ Porphyrins: } \\
\hline -5-ALA/ALA + EDTA-2Na & LED & $635 / 410$ & $30 / 164.5$ & $162 / 9$ & $6.5 / 4$ & {$[55,109]$} \\
\hline - TMPyP & LED/THL & $525 / 300-800$ & $50 / 500$ & $150 / 210$ & $6 / 6$ & {$[51,110]$} \\
\hline - Photofrin $/ \mathrm{Cl}_{2} \mathrm{PEt}$ & LED & $415 / 420$ & $50 / 2.8$ & $10 / 10$ & $7 / 3$ & {$[33,111]$} \\
\hline - TAPP/Tetra-Py ${ }^{+}-\mathrm{Me}$ & $\begin{array}{l}\text { THL/OSRAM } \\
\text { array }\end{array}$ & $\begin{array}{l}350-700 / 380- \\
700\end{array}$ & $25.2 / 4 / 4$ & $180 / 43.2 / 64.8$ & $3 / 8.1 / 8$ & {$[43,49,112]$} \\
\hline \multicolumn{7}{|l|}{ Phenothiazines: } \\
\hline$-\mathrm{MB}$ & $\begin{array}{l}\mathrm{He}-\mathrm{Ne} \\
\text { laser/PDT-1200 }\end{array}$ & $632.6 / 560-780$ & $15.2 / 100$ & $18.2 / 50$ & $5.6 / 5$ & {$[113,114]$} \\
\hline$-\mathrm{NMB} / \mathrm{TBO}$ & LED/THL & $525 / 300-800$ & $50 / 500$ & $100 / 210$ & $3 / 7$ & {$[51,110]$} \\
\hline \multicolumn{7}{|c|}{$\begin{array}{l}\text { aBLT: Antimicrobial blue light treatment; AlGalnP diode laser: Aluminum gallium indium phosphide diode laser; DL: Diode laser; He-Ne laser: Helium-neon laser; HYP: Hypericin; ICG: } \\
\text { Indocyanine green; KI: Potassium iodide; LC16: C60 fullerene derivate; LED: Light-emitting diode; ND: No data; NMB: New methylene blue; NIR: Near-infrared; NR: Neutral red; NRBr: } \\
\text { Monobrominated neutral red; PpIX: Protoporphyrin IX; PPArga: Protoporphyrin IX diarginate; PS: Photosensitizer; QTH: Quartz-tungsten-halogen; RB: Rose Bengal; TBO: Toluidine blue } \\
\text { ortho; THL: Tungsten-halogen lamp; UVA: Ultraviolet A; ZnPC: Zinc phthalocyanine. }\end{array}$} \\
\hline
\end{tabular}




\begin{tabular}{|c|c|c|c|c|c|c|}
\hline Photosensitizer & Light source & $\begin{array}{l}\text { Wavelength } \\
(\mathrm{nm})\end{array}$ & $\begin{array}{l}\text { Irradiance } \\
\left(\mathrm{mW} / \mathrm{cm}^{2}\right)\end{array}$ & Fluence $\left(\mathrm{J} / \mathrm{cm}^{2}\right)$ & Max. reduction $\left(\log _{10}\right)$ & Refs. \\
\hline \multicolumn{7}{|l|}{ Phthalocyanines: } \\
\hline - ZnPc derivative/LuPc-5 & $\begin{array}{l}\text { THL/DLs and } \\
\text { LEDs }\end{array}$ & $<610 / 665$ & $40 / 60$ & $48 / 50$ & $4 / \sim 6$ & {$[97,115]$} \\
\hline \multicolumn{7}{|l|}{ Xanthenes: } \\
\hline$-\mathrm{RB} / \mathrm{RB}+\mathrm{KI}$ & LED/white lamp & $525 / 540$ & $50 / 100$ & $150 / 10$ & $6 / 7$ & {$[51,56]$} \\
\hline \multicolumn{7}{|l|}{ Others: } \\
\hline - TLD1411/Phenalen-1-one & LED/noncoherent & $525 / 380-480$ & $50 / 20$ & $100 / 1.2$ & $6 / 5$ & {$[51,116]$} \\
\hline - BODIPY & THL/noncoherent & $400 / 400-700$ & $47.5 / 65$ & $171 / 118$ & $7 / 4.5$ & {$[50,31]$} \\
\hline - Ryboflavin derivates & Noncoherent & $380-600$ & 50 & 1.5 & 6.8 & [22] \\
\hline \multicolumn{7}{|l|}{ Enterobacter spp. } \\
\hline aBLT & LED & 400 & 60 & $54-108$ & $>5$ & [42] \\
\hline Phenothiazines: & $\begin{array}{l}\text { LED/AIGaInP } \\
\text { diode laser/LED }\end{array}$ & $660 / 660 / 650$ & $25 / 1428.6 / 16.7$ & $50 / 200 / \mathrm{ND}$ & $5-6$ & {$[59,60,117]$} \\
\hline \multicolumn{7}{|l|}{$-\mathrm{MB}$} \\
\hline \multicolumn{7}{|l|}{ Xanthenes: } \\
\hline$-\mathrm{RB}$ & LED & 460 & ND & ND & $>7$ & [61] \\
\hline
\end{tabular}

aBLT: Antimicrobial blue light treatment; AlGalnP diode laser: Aluminum gallium indium phosphide diode laser; DL: Diode laser; He-Ne laser: Helium-neon laser; HYP: Hypericin; ICG: Indocyanine green; KI: Potassium iodide; LC16: C60 fullerene derivate; LED: Light-emitting diode; ND: No data; NMB: New methylene blue; NIR: Near-infrared; NR: Neutral red; NRBr: Monobrominated neutral red; PpIX: Protoporphyrin IX; PPArg2: Protoporphyrin IX diarginate; PS: Photosensitizer; QTH: Quartz-tungsten-halogen; RB: Rose Bengal; TBO: Toluidine blue ortho; THL: Tungsten-halogen lamp; UVA: Ultraviolet A; ZnPC: Zinc phthalocyanine.

light $\left(633 \pm 10 \mathrm{~nm}, 288 \mathrm{~J} / \mathrm{cm}^{2}\right)$. Treatment with 5 -ALA resulted in $5.37 \log _{10}$ reduction in survival fraction for VRE clinical isolate and $5.22 \log _{10}$ for the reference E. faecalis strain. Slightly lower efficiency was observed in case of MAL treatment reaching 5.02 and $4.91 \log _{10}$ reduction in survival fraction for the clinical and reference strains, respectively [11]. Another study concerning in vitro planktonic conditions was reported by Borba et al., who described the effectiveness of erythrosine and LED lamp emitting blue wavelength light (440-480 nm). Complete eradication in tested $E$. faecalis strains was observed when cells were exposed to $5 \mu \mathrm{M}$ erythrosine followed with $240 \mathrm{~s}$ of irradiation $\left(\sim 9.6 \log _{10}\right.$ reduction in cell viability) [12]. In vitro efficacy of aPDI was also confirmed using biofilm culture conditions. In 2013, Cieplik et al. described the aPDI effectiveness toward $E$. faecalis biofilm using newly synthesized PS - SAPYR. E. faecalis biofilm formed in 96-well polystyrene culture plates for $72 \mathrm{~h}$ and exposed to SAPYR and light irradiation $(360-410 \mathrm{~nm})$ revealed significant reduction in cell viability $\left(\geq 5 \log _{10}\right.$ CFU reduction) [13]. Recently, Diogo et al. described aPDI antibiofilm effectiveness wherein four different PSs were tested (rose Bengal, RB; toluidine blue O, TBO; 5,10,15,20-Tetrakis(1-methyl-4-pyridinio)porphyrin tetra ( $p$ toluenesulfonate, TMPyP and modified chlorophyll $\left.-\mathrm{Zn}(\mathrm{II}) \mathrm{e}_{6} \mathrm{Me}\right)$. The highest efficacy reaching approximately $1 \log _{10}$ reduction in viable cell was reported in case of RB activated with green $557 \mathrm{~nm}$ light $\left(3780 \mathrm{~J} / \mathrm{cm}^{2}\right)$ and of TBO/TMPyP/Zn(II) $\mathrm{e}_{6}$ Me activated with red $627 \mathrm{~nm}$ light $\left(3150 \mathrm{~J} / \mathrm{cm}^{2}\right)$ [14]. Similar results with reduction in cell viability by $<1 \log _{10} \mathrm{CFU} / \mathrm{ml}$ were obtained for TBO against enterococcal biofilm and reported by López-Jimènez et al. Higher antibiofilm activity was demonstrated using diode laser light in combination with methylene blue (MB), reaching reduction of $E$. faecalis biofilm by approximately $1-2 \log _{10} \mathrm{CFU} / \mathrm{ml}$ [15]. In vitro aPDI efficacy was also confirmed using ex vivo model. Cieplik et al. designed a tooth model that included a human premolar, first and second molar. The glass tube containig E. faecalis reference strain and PS was placed in the distal root canal of presented model. TMPyP and MB were tested in the same concentrations $(10 \mu \mathrm{M})$ and the light doses were 2.4 and $4.54 \mathrm{~J} / \mathrm{cm}^{2}$ in case of TMPyP and MB, respectively. Obtained results indicated that application of blue light and TMPyP is slightly more effective $\left(6.5 \log _{10} \mathrm{CFU}\right)$ than red light and MB $\left(5.8 \log _{10} \mathrm{CFU}\right)$ to effectively eradicate $E$. faecalis in single tooth and whole tooth model [16]. Another study employing human tooth model was conducted by Tennert et al. in 2014. In this study human front teeth and premolars were selected. Root canals of all teeth were infected with clinical isolate of $E$. faecalis for $72 \mathrm{~h}$ to biofilm formation. The effectiveness of aPDI treatment was checked for both primary and secondary endodontic infections. Application of TBO and exposure to irradiation with red light $(635 \mathrm{~nm})$ resulted in cell viability reduction $>1 \log _{10} \mathrm{CFU} / \mathrm{ml}$ in primary infections and 
Review Nakonieczna, Wozniak, Pieranski, Rapacka-Zdonczyk, Ogonowska \& Grinholc

Table 2. Antimicrobial photodynamic inactivation of ESKAPE pathogens in biofilm cultures.

\begin{tabular}{|c|c|c|c|c|c|c|c|}
\hline Photosensitizer & Light source & $\begin{array}{l}\text { Wavelength } \\
(\mathrm{nm})\end{array}$ & $\begin{array}{l}\text { Irradiance } \\
\left(\mathrm{mW} / \mathrm{cm}^{2}\right)\end{array}$ & Fluence $\left(\mathrm{J} / \mathrm{cm}^{2}\right)$ & Biofilm formation method & $\begin{array}{l}\text { Max. reduction } \\
\left(\log _{10}\right)\end{array}$ & Ref. \\
\hline - TMPyP & LED & 627 & 35 & 3150 & $\begin{array}{l}\text { 96-well plates, } 48 \mathrm{~h}, 37^{\circ} \mathrm{C} \text {, without } \\
\text { agitation }\end{array}$ & $<1$ & [14] \\
\hline \multicolumn{8}{|l|}{ Phenothiazines: } \\
\hline- & LED & $628 / 627$ & $\mathrm{ND} / 35$ & $106 / 3150$ & $\begin{array}{l}\text { 24-well plates, } 24 \mathrm{~h}, 37^{\circ} \mathrm{C} \text {, shaking } \\
(60 \mathrm{rpm}) / 96 \text {-well plates, } 48 \mathrm{~h}, 37^{\circ} \mathrm{C} \text {, } \\
\text { without agitation }\end{array}$ & $<1$ & {$[14,15]$} \\
\hline$-\mathrm{MB}$ & DL & 670 & ND & 271 & $\begin{array}{l}\text { 24-well plates, } 24 \mathrm{~h}, 37^{\circ} \mathrm{C} \text {, shaking } \\
(60 \mathrm{rpm})\end{array}$ & $>1$ & [15] \\
\hline \multicolumn{8}{|l|}{ Xanthenes: } \\
\hline - SAPYR & Noncoherent & $360-410$ & 600 & ND & 96-well plates, $72 \mathrm{~h}, 37^{\circ} \mathrm{C}$ & $\geq 5$ & [13] \\
\hline \multicolumn{8}{|l|}{$\begin{array}{l}\text { Staphylococcus } \\
\text { aureus }\end{array}$} \\
\hline aBLT & LED & $400 / 455 / 405$ & $60 / 75 / 1.05$ & $162 / 45 / 63$ & $\begin{array}{l}\text { PEGs-lids, static, } 72 \mathrm{~h}, 33^{\circ} \mathrm{C} / 24 \text {-well } \\
\text { plates with compact bone, } 14 \text { days, } \\
35^{\circ} \mathrm{C} / 12 \text {-well plates with titanium discs, } \\
48 \mathrm{~h}, 35^{\circ} \mathrm{C}\end{array}$ & $<1 / 3.2 / 1.55$ & {$[42,118,119]$} \\
\hline \multicolumn{8}{|l|}{ Phenothiazines: } \\
\hline$-\mathrm{MB}$ & $\begin{array}{l}\text { InGaAIP } \\
\text { laser/DL }\end{array}$ & $660 / 635$ & $400 / 1.41$ & $257 / 84.6$ & $\begin{array}{l}\text { 24-well plates with compact and } \\
\text { cancellous bone, } 14 \text { days, } 37^{\circ} \mathrm{C} / 12 \text {-well } \\
\text { plates with titanium discs, } 48 \mathrm{~h}, 35^{\circ} \mathrm{C}\end{array}$ & $3.06 / 2.43$ & {$[27,119]$} \\
\hline $\begin{array}{l}-\mathrm{Ru}(\mathrm{II}) \text { complex } \\
3\end{array}$ & $\begin{array}{l}\text { Dual- } \\
\text { wavelength } \\
\text { laser }\end{array}$ & 457 and 532 & 40 & 24 & 96 -well plates, $24 \mathrm{~h}, 37^{\circ} \mathrm{C}$ & $\sim 1$ & [104] \\
\hline$-M G$ & InGaAlP laser & $660 \mathrm{~nm}$ & 400 & $428.5 / 257$ & $\begin{array}{l}\text { 24-well plates containing compact and } \\
\text { cancellous bone, } 14 \text { days, } 37^{\circ} \mathrm{C}\end{array}$ & $3-4 / 4.46$ & {$[27,118]$} \\
\hline \multicolumn{8}{|l|}{$\begin{array}{l}\text { Klebsiella } \\
\text { pneumoniae }\end{array}$} \\
\hline \multicolumn{8}{|l|}{ Porphyrins: } \\
\hline - 5-ALA, MAL & White & $400-780$ & 100 & 360 & 24-well plate, $24 \mathrm{~h}, 37^{\circ} \mathrm{C}$ & $3.49-4.25$ & [34] \\
\hline \multicolumn{8}{|l|}{ Phenothiazines: } \\
\hline $\begin{array}{l}\text { - TBO, Azure A, } \\
\text { NMB }\end{array}$ & Laser & 630 & 130 & 39 & $96-$ well plates, $48 \mathrm{~h}, 37^{\circ} \mathrm{C}$ & $<1$ & [32] \\
\hline \multicolumn{8}{|l|}{$\begin{array}{l}\text { Acinetobacter } \\
\text { baumannii }\end{array}$} \\
\hline aBLT & LED & $415 / 400$ & $100 / 60$ & $432 / 216$ & $\begin{array}{l}\text { Microtiter plate, static } 24 \text { or } 72 \mathrm{~h} \text {, } \\
37^{\circ} \mathrm{C} / \text { pegs-lids, static, } 72 \mathrm{~h}, 33^{\circ} \mathrm{C}\end{array}$ & $3.18 /<1.5$ & {$[42,45]$} \\
\hline
\end{tabular}




\begin{tabular}{|c|c|c|c|c|c|c|c|}
\hline Photosensitizer & Light source & $\begin{array}{l}\text { Wavelength } \\
(\mathrm{nm})\end{array}$ & $\begin{array}{l}\text { Irradiance } \\
\left(\mathrm{mW} / \mathrm{cm}^{2}\right)\end{array}$ & Fluence $\left(\mathrm{J} / \mathrm{cm}^{2}\right)$ & Biofilm formation method & $\begin{array}{l}\text { Max. reduction } \\
\left(\log _{10}\right)\end{array}$ & Ref. \\
\hline \multicolumn{8}{|l|}{$\begin{array}{l}\text { Pseudomonas } \\
\text { aeruginosa }\end{array}$} \\
\hline aBLT & LED & $400 / 415$ & $60 / 100$ & $108 / 432$ & $\begin{array}{l}\text { PEG-lids, static, } 72 \mathrm{~h}, 33^{\circ} \mathrm{C} / \text { microtiter } \\
\text { plate, static } 24 \text { or } 72 \mathrm{~h}, 37^{\circ} \mathrm{C}\end{array}$ & $<1 / 3.02$ & {$[42,45]$} \\
\hline \multicolumn{8}{|l|}{ Porphyrin: } \\
\hline $\begin{array}{l}- \text { TAPP/Tetra- } \\
\text { Py+ }^{+} \text {-Me }\end{array}$ & $\begin{array}{l}\text { THL/OSRAM } \\
\text { lamps }\end{array}$ & $\begin{array}{l}350-700 / 380- \\
700\end{array}$ & $25.2 / 4$ & $180 / 21.6$ & $\begin{array}{l}\text { Microtiter plates, } 24 \mathrm{~h}, 37^{\circ} \mathrm{C} \\
\text { static/stirring }(130 \mathrm{rpm})\end{array}$ & $3 / 2.8$ & {$[49,112]$} \\
\hline \multicolumn{8}{|l|}{ Phenothiazines: } \\
\hline$-\mathrm{MB}$ & $\begin{array}{l}\text { Nonthermal } \\
\text { laser }\end{array}$ & 670 & 150 & 72 & $\begin{array}{l}\text { Maxillary sinus model, shaking, } 24 \mathrm{~h}, \\
35^{\circ} \mathrm{C}\end{array}$ & 3.9 & [26] \\
\hline \multicolumn{8}{|l|}{ Others: } \\
\hline $\begin{array}{l}- \text { GD11 - } \\
\text { BODIPY }\end{array}$ & THL & 400 & 48 & 171 & PEG-lids, static, $24 \mathrm{~h}, 37^{\circ} \mathrm{C}$ & 4 & [50] \\
\hline \multicolumn{8}{|l|}{$\begin{array}{l}\text { Enterobacter } \\
\text { spp. }\end{array}$} \\
\hline aBLT & LED & 400 & 60 & 162 & PEG-lids, static, $72 \mathrm{~h}, 33^{\circ} \mathrm{C}$ & $<1$ & [42] \\
\hline
\end{tabular}

aBLT: Antimicrobial blue light treatment; AIGalnP diode laser: Aluminum gallium indium phosphide diode laser; DL: Diode laser; InGaAIP laser: Indium-gallium-aluminum phosphide laser; LED: Light-emitting diode; ND: No data; THL: Tungsten-halogen lamp.

$3 \log _{10} \mathrm{CFU} / \mathrm{ml}$ in secondary infections, respectively [17]. Above-mentioned studies clearly indicate that aPDI could effectively inactivate Enterococcus spp. and serve as alternative treatment option against enterococcal infections.

\section{Staphylococcus aureus}

S. aureus, mainly MRSA is one of the most important MDR human pathogen. The number of MRSA infections, both hospital and community acquired, is growing worldwide and they are frequently difficult to treat $[18,19]$. More than $90 \%$ of $S$. aureus clinical isolates are resistant to penicillin and $60 \%$ of them are MRSA [20]. 60 years after the introduction of vancomycin strains of reduced susceptibility or even resistant to glycopeptides are reported [21]. Due to the ability of bacteria to rapid acquisition of antibiotic resistance scientists are facing with great need of new therapies development. One of a very promising, noninvasive therapeutic option to cure $S$. aureus infections is aPDI. In the last 5 years, many conventional and novel PSs derivatives with appropriate wavelength light absorption were tested in vitro and in vivo. Maisch et al. synthesized two new flavin derivatives (FLASH-01a and FLASH-07a). These PSs were very effective against MRSA when irradiated with noncoherent light source $\left(380-600 \mathrm{~nm}, 50 \mathrm{~mW} / \mathrm{cm}^{2}\right)$ resulting in 5-6 $\log _{10}$ reduction of viable cells [22]. Other examples of novel PSs are 5-(Ethylamino)-9-diethylaminobenzo[a]phenothiazinium chloride (EtNBS) derivatives synthesized by Vecchio et al. Five out of six were very successful in decreasing $S$. aureus viability $\left(3-6 \log _{10} \mathrm{CFU} / \mathrm{ml}\right.$ ) when employing red light $(635 \mathrm{~nm})$ at fluence $10 \mathrm{~J} / \mathrm{cm}^{2}$ and irradiance of $50 \mathrm{~mW} / \mathrm{cm}^{2}$ [23]. Next, studies by Urrutia et al. describe the synthesis of monobrominated derivative of neutral red (NRBr). Phototoxicity of $\mathrm{NRBr}$ was higher than that of $\mathrm{NR}$ and effected in complete eradication of MRSA after $30 \mathrm{~min}$ of illumination [24]. Very interesting findings were reported by Agazzi et al., who synthesized two cationic derivatives of 2,6-diiodo-1,3,5,7-tetramethyl-8-( $N$-benzyl4-pyridyl)-4,4'-difluoroboradiazaindacene (BODIPY) and revealed that exposure of $S$. aureus to visible light for 5 min resulted in significant reduction in cell survival $\left(>5 \log _{10} \mathrm{CFU} / \mathrm{ml}\right)$ [25]. Considering biofilm conditions, Biel $e$ al. conducted experiments where MRSA biofilms were grown in an anatomically accurate maxillary sinus model to mimic in vivo conditions of chronic rhinosinusitis. Indicated biofilms were illuminated with $670 \mathrm{~nm}$ nonthermal laser light using Sinuwave ${ }^{\circledR}$ ballon catherer in the presence of MB. A single $0.03 \% \mathrm{MB}$ aPDI treatment, at irradiance of $50 \mathrm{~mW} / \mathrm{cm}^{2}$, for $8 \mathrm{~min}$, resulted in a $4.1 \log _{10} \mathrm{CFU}$ reduction [26]. In another biofilm-related study, the effectiveness of aPDI with 660-nm laser combined with MB, TBO and malachite green (MG) dyes against MRSA biofilms formed in compact and cancellous bones was tested [27]. After incubation for 14 days in the 24-well plates biofilms were illuminated with light fluence of $257 \mathrm{~J} / \mathrm{cm}^{2}$ and irradiance of $400 \mathrm{~mW} / \mathrm{cm}^{2}$. All experimental treatments resulted in significant reduction in $\mathrm{CFU} / \mathrm{ml} \log _{10}$ in comparison to the control group. For the compact bones, the highest therapeutic effect was observed in case of MG dye, resulting in $4.46 \log _{10}$ reduction, while for the cancellous groups in case of $\mathrm{MB}\left(3.06 \log _{10}\right.$ reduction) [27]. The antimicrobial effectiveness of aPDI 
Review Nakonieczna, Wozniak, Pieranski, Rapacka-Zdonczyk, Ogonowska \& Grinholc

Table 3. Antimicrobial photodynamic inactivation of ESKAPE pathogens in in vivo/ex vivo studies.

\begin{tabular}{|c|c|c|c|c|c|c|c|c|}
\hline Photosensitizer & Light source & $\begin{array}{l}\text { Wavelength } \\
(\mathrm{nm})\end{array}$ & $\begin{array}{l}\text { Irradiance } \\
\left(\mathrm{mW} / \mathrm{cm}^{2}\right)\end{array}$ & Fluence $\left(\mathrm{J} / \mathrm{cm}^{2}\right)$ & Model characteristics & $\begin{array}{l}\text { Interval } \\
\text { between } \\
\text { microbial } \\
\text { inoculation and } \\
\text { aPDI }\end{array}$ & $\begin{array}{l}\text { Max. } \\
\text { reduction } \\
\left(\log _{10}\right)\end{array}$ & Ref. \\
\hline \multicolumn{9}{|l|}{$\begin{array}{l}\text { Enterococcus } \\
\text { faecalis }\end{array}$} \\
\hline \multicolumn{9}{|l|}{ Porphyrins: } \\
\hline$-\mathrm{MB}$ & PDT 1200L & $600-700$ & 37.8 & 4.54 & Human tooth & ND & $5.8-7.2$ & [16] \\
\hline - ТВO/ТВO & LED/LED & $635 / 628$ & ND/2000 & ND & Human root canals & $72 / 72 \mathrm{~h}$ & $3 / 1-2$ & {$[17,121]$} \\
\hline \multicolumn{9}{|l|}{$\begin{array}{l}\text { Staphylococcus } \\
\text { aureus }\end{array}$} \\
\hline \multicolumn{9}{|l|}{ Porphyrin: } \\
\hline \multicolumn{9}{|l|}{ Phthalocyanine: } \\
\hline - RLP068/Cl & Lumacare lamp & 690 & 100 & 84 & Mouse skin abrasions & $30 \mathrm{~min}$ & 2.9 & [96] \\
\hline \multicolumn{9}{|l|}{ Fullerenes: } \\
\hline $\begin{array}{l}\text { - Fulleropyrroli- } \\
\text { dine }\end{array}$ & LED & 525 & 50 & 100 & Mouse infected wound & $30 \mathrm{~min}$ & 2 & [28] \\
\hline \multicolumn{9}{|l|}{ Others: } \\
\hline $\begin{array}{l}\text { - Ru(II)-based } \\
\text { TLD1411 }\end{array}$ & Noncoherent & 525 & 50 & 100 & Mouse infected wound & $30 \mathrm{~min}$ & $<1$ & [51] \\
\hline \multicolumn{9}{|l|}{$\begin{array}{l}\text { Acinetobacter } \\
\text { baumannii }\end{array}$} \\
\hline aBLT & LED & 415 & $100 / 14.6$ & $360-540 / 55.8$ & Mouse burn wound & $\begin{array}{l}24 \mathrm{~h}, \\
48 \mathrm{~h} / 30 \mathrm{~min}\end{array}$ & $3 / 4.4$ & {$[45,106]$} \\
\hline \multicolumn{9}{|l|}{$\begin{array}{l}\text { Pseudomonas } \\
\text { aeruginosa }\end{array}$} \\
\hline aBLT & LED & 415 & 100 & $304 / 144$ & $\begin{array}{l}\text { Rabbit keratitis/mouse } \\
\text { keratitis }\end{array}$ & $24 \mathrm{~h}$ & $3 / 2.5$ & [122] \\
\hline $\mathrm{aBLT}$ & LED & 415 & $14.6 / 100$ & $55.8 / 48$ & Mouse burn/skin abrasion & $30 \mathrm{~min}$ & $3.5 / 5$ & {$[52,108]$} \\
\hline \multicolumn{9}{|l|}{ Porphyrin: } \\
\hline $\begin{array}{l}- \\
\text { ALA/ALA + EDTA- } \\
2 \mathrm{Na}\end{array}$ & LED & $630 / 410$ & $\mathrm{ND} / 164.5$ & $80 / 9$ & Human/mouse skin ulcers & $\mathrm{ND} / 2$ days & $\sim 2 / 5$ & {$[55,123]$} \\
\hline \multicolumn{9}{|l|}{ Xanthene: } \\
\hline$-\mathrm{RB}+\mathrm{KI}$ & Lumacare lamp & 540 & 100 & 20 & Mouse skin abrasion wounds & $30 \mathrm{~min}$ & 6 & [56] \\
\hline \multicolumn{9}{|l|}{ Others: } \\
\hline - TLD1411 & LED & 525 & 50 & 100 & Mouse cut wound & $30 \mathrm{~min}$ & $<1$ & [51] \\
\hline
\end{tabular}

4 Conjugate: 5,10,15,20-Trakis(4-((s)-2,6-diaminohexanamido)-phenyl) porphyrin; 5-ALA: 5-Aminolevulinic acid; aBLT: Antimicrobial blue light treatment; EDTA-2Na: Ethylenediaminetetraacetic acid disodium salt; KI: Potassium iodide; LC16: C60 fullerene derivate; LED: Light-emitting diode; MB: Methylene blue; ND: No data; RB: Rose Bengal; RLP068/Cl: Tetracationic Zn(II) phthalocyanine chloride; TBO: Toluidine blue ortho; TLD1411: [Ru(2,2'-bipyridine)2(2-(2',2 $1: 51,2 \prime^{\prime}$-terthiophene)-imidazo[4,5-f] $[1,10]$ phenanthroline)]2+; TMPyP: 5, 10,15,20-Tetrakis(1methyl-4-pyridinio)porphyrin tetra(p-toluenesulfonate). 
toward $S$. aureus has also been demonstrated in numerous in vivo studies. Our group examined in vitro efficacy of a $\mathrm{C}_{60}$ fullerene derivative (fulleropyrrolidine)-mediated irradiation with white light. Illumination of MRSA samples was performed using visible light source over wavelength range of $385-780 \mathrm{~nm}$ (irradiance $267 \mathrm{~mW} / \mathrm{cm}^{2}$, fluence $160 \mathrm{~J} / \mathrm{cm}^{2}$ ) that effected with significant photoinactivation of $S$. aureus (3.5 to $>6 \log _{10}$ unit reduction). Afterward, in vivo experiments using bioluminescent MRSA strain were performed, to analyze if high in vitro effectiveness could be translated into in vivo activity. In the aPDI-treated mice, the therapeutic effect was observed: after 24-h postirradiation bioluminescent signal decreased dramatically, reaching background level [28]. Another impressive example of in vivo studies was performed by Morimoto et al. Mouse model of MRSA-infected ulcer was used to test the effectiveness of 5-ALA-mediated aPDI. On each ulcer, the silicone splint was placed to center the wound and to minimize contracture. The ulcers were next inoculated with MRSA $\left(10^{10} \mathrm{CFU} / \mathrm{cm}^{2}\right)$ and an occlusive dressing was covered. One day after infection, 5-ALA was administered via intraperitoneal injection. Then, photoinactivation using LED with major wavelength of $410 \mathrm{~nm}$ (irradiation of $164.5 \mathrm{~mW} / \mathrm{cm}^{2}$, fluence of $50 \mathrm{~J} / \mathrm{cm}^{2}$ ) was performed every day. After 7 days, post-aPDI the viable bacteria in ulcer tissue was counted and $2 \log _{10}$ units of reduction was observed when compared with nontreated control [29]. As indicated above, both planktonic as well as biofilm and in vivo studies confirm that aPDI could be considered effective therapeutic option against staphylococcal infections.

\section{Klebsiella spp.}

Klebsiella pneumoniae is an opportunistic pathogen causing hospital-acquired and community-acquired infections, mainly UTIs and pneumonia. The global concern related to this microbial species focuses on ESBL and carbapenemase-producing strains. There are several known types of $K$. pneumoniae carbapenemase (KPC) conferring moderate to high (KPC-1) or high resistance to carbapenems (KPC-2, KPC-3). Also, recently identified metallo-lactamases with an example of New Delhi metallo- $\beta$-lactamase-1 (NMD-1) have been reported first on Indian subcontinent, and further in Europe, Middle East, Africa, Asia and America, exemplifying fast spreading of antimicrobial resistance. The whole doomed scenario is filled by the production of several virulence factors by this species, including capsule polysaccharide, aerobactin, fimbriae and outer membrane protein A, all playing a critical role in mammalian cell invasion. The success in causing UTI and infecting respiratory tract is attributed to the ability of forming a biofilm, which results in dramatic increase in resistance to currently available antimicrobial agents. The whole picture is even more complex as $K$. pneumoniae prefers to form mixed species biofilm as compared to isolated one. For example, $K$. pneumoniae is able to form stable biofilm with $P$. aeruginosa, where specific spatial distribution of each species was reported. Several groups have shown mixed $K$. pneumoniae biofilms with Proteus mirabilis, Candida albicans, Streptococcus, however, the complexity of the interactions in such interspecies biofilms still awaits to be resolved.

As a first-line antibiotic for the treatment of the most dangerous carbapenem-resistant $K$. pneumoniae, high doses of carbapenems are applied, or the same combined with a range of other antibiotics, such as colistin, tigecycline, gentamicin or fosfomycin (second-line antibiotics). Some new generation cephalosporins have shown potency against carbapenem-resistant $K$. pneumoniae in vitro, when combined with tazobactam. However, alternative control methods, such as aPDI, should be proposed along with the discovery of new antibiotics or mixtures thereof. It has been not many years since aPDI started to be widely explored on ESKAPE species, including $K$. pneumoniae. There have been several types of light-activated compounds investigated with respect to $K$. pneumoniae photoinactivation: BODIPY, phenothiazines, porphyrin derivatives and their precursors (5-ALA, MAL), phthalocyanines. Recently, an interesting type of molecules was studied - indole derivatives that present a new structural scaffold for aPDI application. The activity of these compounds against Gram-negative species was only possible in the presence of polymyxin $\mathrm{E}$ [30]. From the newest scaffolds studied in terms of antimicrobial activity, boron dipyrromethene (BODIPY)-based compounds present an attractive option, as they exhibit several characteristics attractive for aPDI, including stability at physiological conditions. With the use of DIMPy-BODIPY $(2.5 \mu \mathrm{M})$, approximately $4 \log _{10}$ reduction in viable $K$. pneumoniae cells was obtained. One of the drawbacks of DIMPy-BODIPY is their relatively low ${ }^{1} \mathrm{O}_{2}$ production accounting for $11 \%$ [31], which seems to be most desired ROS in terms of aPDI application. More commonly studied in aPDI are phenothiazines, which in case of $K$. pneumoniae do not present spectacular results ( $\sim 3 \log _{10}$ reduction) [32]. One has to remember, however, that even these PSs that do not significantly reduce the number of bacterial cells but possess good photochemical properties, can become efficient 'killers' when applied together with nontoxic compounds, like potassium iodide (KI). The Photophrin, a US FDA-approved drug for treating cancers, can become efficient against $K$. pneumoniae in the presence of KI $\left(\sim 6 \log _{10}\right.$ reduction in viable $K$. pneumoniae cells) [33]. From the representatives of FDA-approved drugs, 5-ALA or MAL constitute 
an attractive option of PSs as their application resulted in more than $3 \log _{10}$ after application of $10 \mathrm{mM}$ ALA. Of interest, ESBL-producing and ESBL-nonproducing strains were killed with similar efficacy. In case of MAL applications, the results were even better, and exceeded the value of $4 \log _{10}$ reduction in cell number [34]. The 5-ALA or MAL-based aPDI application seems to be attractive from the clinical point of view as beside the fact of the FDA/EMEA approval, these PSs can be used along with white light, which constitutes universal light source. Considering great difficulties for treatment of carbapenem-resistant $K$. pnaumoniae (KPC) an interesting

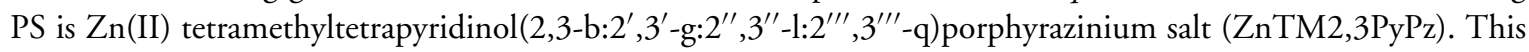
phthalocyanine reduced the bacterial cell number by $4.3 \operatorname{logs}(3 \mu \mathrm{M})$. Given the fact that phthalocyanines are poorly water soluble, ZnTM2,3PyPz showed relatively high photokilling properties in aqueous solution [35]. An interesting aPDI option was recently studied with the use of vitamin K5 as a PS. Combination of vitamin K5 and UVA resulted in 7 logs decrease in K. pnaumoniae survival, but also in other Gram-negative species [36]. The only drawback of the study seems to be the application of UVA, which is known to negatively influence the DNA structure.

Only two experimental work concerns biofilm analysis upon aPDI treatment: with the use of 5-ALA/MAL and phenothiazines. Whereas in the first case appreciable efficacy of approximately $4 \log _{10}$ reduction $(10 \mathrm{mM}$ MAL) was obtained for both ESBL-producing and ESBL-nonproducing clinical isolate [34], there was only slight antibiofilm activity for each of phenothazines studied (TBO; Azure A, AA; and new methylene blue, NMB) [32].

Recently, a very interesting in vivo study was published focusing on treating reptile infections. K. pneumoniae, resistant to ten antibiotics, was identified as one of the species at the infection site. After 3-month aPDI treatment (once a week) with MB and red laser, all animals (three) improved and showed reduction of inflammatory signs, although signs of reinfections on the first month was also observable [37].

\section{Acinetobacter baumannii}

In 2017, WHO presented the list of pathogens for which new antimicrobial agents are urgently needed, therefore, it included for the highest - critical priority carbapenem-resistant $A$. baumannii. This Gram-negative, nonfermentative, catalase-positive coccobacilli is well distributed in environment and it is known as an etiological agent of hospital-acquired infections [38,39]. Due to increasing and fast developing resistance to routinely applied antibiotics, this pathogen is widely responsible for skin, bloodstream and UTIs, especially in intensive care units [40]. Alternative method of fighting with this opportunistic pathogen can be aPDI. Its antimicrobial effectiveness was repeatedly presented in in vitro and in vivo studies performed for biofilm and planktonic cultures. Most of the studies refer to photoinactivation of $A$. baumannii planktonic cultures with the administration of exogenous PSs. Studies by Huang et al. presented the effectiveness of aPDI employing cationic bacteriochlorins (BC37, BC38, BC39) that are monosubstituted PSs [41]. Phototreatment with mentioned bacteriochlorins in concentration ranging from 1 to $5 \mu \mathrm{M}$ and light fluence $10 \mathrm{~J} / \mathrm{cm}^{2}(\lambda: 750-800 \mathrm{~nm})$ gave significant reduction in viable cell count, varying from 5 to $6 \log _{10}$ units. Next, aPDI efficacy employing blue light and endogenously produced porphyrin sensitizers was presented by Halstead et al. for eradication of 12 clinical isolates of $A$. baumannii. This antimicrobial blue light treatment (aBLT; $\lambda: 400 \pm 8.5 \mathrm{~nm}$ ) with light fluence of $108 \mathrm{~J} / \mathrm{cm}^{2}$ resulted in reduction of bacterial viability ranging from 5.8 to $7.6 \log _{10}$ for all tested isolates [42]. Another significant reduction of A. baumannii viability was reported by Almeida et al. in response to bacterial exposure to white light (light fluence $64.8 \mathrm{~J} / \mathrm{cm}^{2}$ ) in the presence of Tetra-Py ${ }^{+}-\mathrm{Me}$ porphyrin [43]. The viability of $A$. baumannii isolated from both hospital wastewater and nonsurgical wounds was reduced by $6 \log _{10}$ upon aPDI treatment [43]. Next, porphyrin derivatives containing 4 lysine residues (4I) and irradiated with red light were confirmed to be effective against planktonic cultures of $A$. baumannii representing different profiles of drug resistance. aPDI employing $4 \mathrm{I}$ and red light fluence of $6 \mathrm{~J} / \mathrm{cm}^{2}$ resulted in 3.77 and $3.83 \log _{10}$ unit reduction in viable cell count, for MDR and wild-type $A$. baumannii strains, respectively [44]. It is also worth mentioning that phenothiazine versus (exemplified with nile blue derivatives, EtNBS) activated with red light exerted significant antimicrobial effect toward planktonic Acinetobacter spp. cultures. The most bactericidal were three out of seven tested derivatives: EtNBS, EtNBS-Ac and EtNBS-G. In this case, red light irradiation resulted in reduced viable cells by 6,5 and $7 \log _{10}$, respectively [23]. The antimicrobial efficacy of aPDI was further presented by Maisch et al., who utilized riboflavin derivatives for phototreatment [22]. Two cationic riboflavin derivatives, namely FLASH- 01a and FLASH-07a, consisting of a different number of positive charges were irradiated with light fluencies of 9 and $4.5 \mathrm{~J} / \mathrm{cm}^{2}$, respectively. aPDI with these derivatives resulted in 6.6 and $6.7 \log _{10}$ reduction in viable count for FLASH-01a and FLaSH-07a, respectively [22]. Furthermore, the efficacy of aPDI against $A$. baumannii was proved for biofilm cultures. In 2016 , Halstead et al. using aBLT $\left(216 \mathrm{~J} / \mathrm{cm}^{2}\right)$ 
reported A. baumannii inactivation by approximately $1.5 \log _{10}$ units when grown in biofilm culture [42]. This efficacy was further enhanced by Wang et al. in 2016 who employed aBLT $\left(432 \mathrm{~J} / \mathrm{cm}^{2}\right)$ against mature (24 and $72 \mathrm{~h}$ old) biofilm culture of bioluminescent $A$. baumannii strain indicating the reduction of cell viability by 3.59 and $3.18 \log _{10}$, in case of 24- and 72-h old biofilms, respectively [45]. Additionally, these findings were confirmed using mouse model of $A$. baumannii burn wound infection. Interestingly, microbial biofilm was allowed to grow in mice wounds for 24 or $48 \mathrm{~h}$ followed by blue light irradiation. In case of $24 \mathrm{~h}$ old biofilm, the applied light fluence was 360 and $540 \mathrm{~J} / \mathrm{cm}^{2}$ for 48 -h old biofilm culture. Biofilms exposed to indicated light fluencies resulted in almost complete elimination of bioluminescence signal indicating the cell viability reduction by $3 \log _{10}$ in comparison to control group [45]. Another valuable example of in vivo studies concerning aPDI against $A$. baumannii was described by Yuan et al. in 2017. Employing mouse model of full-thickness excisional wound, infected with multidrug resistant strain, Yuan et al. proved the high bactericidal effectiveness of amino-acid porphyrin conjugate (4I) [44]. In this case, aPDI exerted reduction of $2.89 \log _{10}$ in cell viability when tested immediately after aPDI treatment. This efficacy was further increased to $3.94 \log _{10}$ of reduction when tested at 4th day of experiment [44]. The described above studies of aPDI inactivation of $A$. baumannii utilizing different light sources, various PSs and culture conditions indicate that aPDI could be potent alternative when searching for novel therapeutic option against drug-resistant Acinetobacter spp.

\section{Pseudomonas aeruginosa}

P. aeruginosa is the second most commonly reported Gram-negative pathogen associated with UTI in intensive care units [46]. Less frequent, but much more severe are bloodstream infections with carbapenem resistant $P$. aeruginosa attributed to mortality up to $18.4 \%$ [47]. Moreover, $P$. aeruginosa can manifest resistance to quinolones, aminoglycosides or polymyxins, as well as multiple drugs (MDR strains) with no drugs available in clinical development [48]. The alternative could be aPDI. The effectiveness of Tetra-Py ${ }^{+}-\mathrm{Me}$ porphyrin activated with visible light was assessed by Beirao et al., who reached $8.1 \log _{10}$ reduction in viable cell count in case of planktonic P. aeruginosa culture employing $10 \mu \mathrm{M}$ concentration of Tetra-Py ${ }^{+}-\mathrm{Me}$ and light fluence of $43.2 \mathrm{~J} / \mathrm{cm}^{2}$ [49]. Similar results, $7 \log _{10}$ reduction, were demonstrated by Orlandi et al. with BODIPY PS at low concentration of $2.5 \mu \mathrm{M}$ and light fluence of $171 \mathrm{~J} / \mathrm{cm}^{2}(\lambda: 400 \mathrm{~nm})$ [50]. Our team also investigated the antimicrobial effectiveness of aPDI with four different PSs activated with visible light $(\lambda: 525 \mathrm{~nm})$ against planktonic $P$. aeruginosa cultures. We reached $6 \log _{10}$ reduction in viable cell count for RB, TMPyP and Ru(II)-based derivative (TLD1411) [51]. Alternative to exogenously administered aPDI is aBLT employing blue light activation of endogenously produced PSs. The bactericidal effectiveness of aBLT $\left(\lambda: 400 \mathrm{~nm}\right.$, light fluence $\left.108 \mathrm{~J} / \mathrm{cm}^{2}\right)$ was assessed by Halstead et al. against five both reference and clinical $P$. aeruginosa isolates. Obtained results indicated the reduction in cell viability varying from 5.59 to $6.55 \log _{10}$ units [42]. aBLT $(\lambda: 415 \mathrm{~nm})$ was also investigated by Amin et al., who received $3.54 \log _{10}$ reduction per cycle in ten cycles of bacterial inactivation and regrowth. Moreover, within mentioned study no evidence of development of $P$. aeruginosa tolerance to aBLT was reported [52]. Our group also investigated aBLT efficacy. We reported $7 \log _{10}$ unit reduction in case of four studied $P$. aeruginosa isolates by employing blue light $(\lambda: 411 \mathrm{~nm})$ fluence of $50 \mathrm{~J} / \mathrm{cm}^{2}$ [53,54]. aBLT effectiveness against $P$. aeruginosa was also confirmed for biofilm cultures. Halstead et al. with the use of aBLT (light fluence $108 \mathrm{~J} / \mathrm{cm}^{2}$ ) reported approximately $1 \log _{10}$ reduction of biofilm seeding in case of studied clinical isolates. The influence of aBLT on P. aeruginosa biofilm formation was also demonstrated by studies of our group indicating that sublethal doses of aBLT can successfully delay biofilm formation [53]. Worthy of note, the reduction in microbial viability by $2.8 \log _{10}$ units was also reported by Beirao et al., who used Tetra-Py+-Me porphyrin activated with visible light for $P$. aeruginosa biofilm treatment [49]. Finally, significant antibiofilm activity was presented by Orlandi et al., who employed BODIPY PS for aPDI treatment reaching $4 \log _{10}$ reduction in viable cells growing in biofilm. Next, to investigate if in vitro studies could be easily translated to clinical applications, some in vivo models were described. Our team utilized and optimized mouse cut wound model imitating chronic wound infection for aPDI treatment [51]. When using TLD1411, $1 \log _{10}$ reduction in bioluminescence level associated with delayed infection development was observed [51]. Our most recent studies describe the application of Caenorhabditis elegans infection with $P$. aeruginosa to investigate antimicrobial efficacy of aBLT treatment. Performed experiments confirm that sublethal doses of aBLT resulted in increased C. elegans survival rate in response to decreased virulence and/or delayed biofilm production upon aBLT exposure [53]. In vivo aBLT efficacy was also investigated by Amin et al., who reported $5 \log _{10}$ reduction of bacterial bioluminescence in case of mouse skin abrasion wound infection [52]. Similar antimicrobial effectiveness was observed by Katayama et al., who reported $5 \log _{10}$ reduction of bacterial count using 5-ALA-induced production of endogenous porphyrins 
activated with $410 \mathrm{~nm}$ wavelength light [55]. Another in vivo study for aPDI efficacy was performed by Wen et al., who applied RB in the presence of KI activated with $540 \mathrm{~nm}$ wavelength light [56]. This application resulted in $6 \log _{10}$ reduction in P. aeruginosa bioluminescence in mouse skin abrasion wounds. Mentioned above studies by Amin et al., Katayama et al. and Wan et al. suggest that aPDI could actually be considered a promising option for P. aeruginosa eradication.

\section{Enterobacter spp.}

Enterobacter species are the etiological agents for an increasing number of healthcare-associated infections with emerging and developing resistance to multiple antimicrobials [57]. These infections are characterized with significant morbidity and mortality [58]. As with other members of the Enterobacteriaceae, drug resistance occurs via ESBL and carbapenemases as well as chromosomal cephalosporinases [57]. Only few antimicrobials are still active against this microorganism; thus, the emergence of aPDI as an alternative seems attractive. There are only few studies concerning photodynamic efficacy toward Enterobacter spp. resulting in significant microbial inactivation. Khan et al. reported $5 \log _{10}$ unit reduction in viable cells when $E$. cloacae was administered with phenothiazine sensitizer, $\mathrm{MB}$, and exposed to light irradiation [59]. Employing the same PS, Carvalho et al. reported $6 \log _{10}$ units reduction in cell viability in vitro when Enterobacter spp. isolated from infected wounds was treated with aPDI [60]. Finally, using xanthen PS, RB, Rossoni et al. reached the E. cloacae viability reduction of approximately $7 \log _{10}[61]$. In addition, when employing aBLT without administration of exogenous PSs, Halstead et al. reported that planktonicphase bacteria were susceptible to aBLT demonstrating $\geq 5 \log _{10}$ decrease in viability [62]. The same research group provided the only existing results concerning photodynamic treatment of Enterobacter spp. when cultured in mature biofilms. Obtained results indicated that bacterial biofilms were highly susceptible to blue light, with significant reduction in cell viability for all isolates and all aBLT exposures $(\lambda: 400 \pm 8.5 \mathrm{~nm})$ [62]. Unfortunately, no in vivo/ex vivo studies concerning aPDI Enterobacter spp. were published so far, nevertheless, described studies warrant further investigations of aPDI as a novel antimicrobial strategy and indicate that it could be successfully used for Enterobacter spp. decontamination applications.

\section{Strategies to potentiate aPDI \\ Potentiation of aPDI by nanotechnology}

Nanotechnology provides an attractive approach leading to improved bactericidal efficacy of aPDI [63-66]. This improvement may result from both enhanced targeted PS delivery to microorganisms via PS-loaded nanoparticles [67] or increased ROS and singlet oxygen quantum yield of the PS via its mixing or covalently binding with nanoparticles [68,69]. In addition, some nanoparticles, in other words, $\mathrm{TiO}_{2}$ or fullerenes, could express photosensitizing activity resulting in effective inactivation of microorganisms [70]. The most widely investigated material used for production of PS nanoparticles is chitosan that is a biodegradable and naturally occurring polymer. Moreover, increased aPDI efficacy benefits from its intrinsic cationic charge leading to enhanced targeted PS delivery to microbial over eukaryotic cells. The successful employment of chitosan-loaded PS was numerously reported in case of various microbial as well as fungal cells [71-73]. Another, and most recent nanotechnology-based approach leading to enhanced aPDI results from conjugation of PSs to gold nanoparticles. In this case, the potentiation of aPDI was confirmed with the employment of mature MRSA biofilms treated with PS-conjugated gold nanoparticles. This report is of high interest as significant achievement $\left(>4 \log _{10}\right.$ extra killing) was observed when compared with free PS-based aPDI [74].

\section{Potentiation of aPDI by inorganic salts}

Another attractive strategy leading to potentiated aPDI was developed by the group of Michael Hamblin who reported that the administration of inorganic salts to the aPDI-treated samples, results in more than $6 \log _{10}$ extra killing. The greatest effect was observed in the case of KI [75], but significant enhancement of aPDI efficacy was also reported when potassium bromide [75], sodium azide [76], sodium thiocyanate [77] and sodium nitrite were employed. Huang et al. indicated that the mechanism underlying the observed potentiation may result from the action of singlet oxygen leading to the generation of iodine radicals and molecular iodine from iodide [33]. In case of sodium azide, the mechanism may result from the generation of azide radical upon the oxidation of azide anion [76]. Numerous in vivo published data supported this potentiation strategy revealing that the aPDI efficacy could, indeed, be significantly improved [75,78,79]. 


\section{Potentiation of aPDI by antimicrobials}

The latest discovery associated with the strategy to enhance the bactericidal effect of aPDI is to demonstrate that aPDI sensitizes microbes to antimicrobials. Numerous studies, both in vitro and in vivo, using a whole range of different categories of antibiotics and PSs, confirmed that this combined therapy may exert spectacular effects. Undoubtedly, the interaction of aPDI with antimicrobials could be assigned as synergy that leads to the eradication of microorganisms using very low (sublethal) concentrations of both PSs and antimicrobials against that the microbes expressed high resistance. Moreover, despite the enhancement of the bactericidal effect, another important effect that can be expected due to the use of aPDI/antimicrobials combined approach may be shortening the treatment time and reducing the rate of microbial drug resistance development. All these issues as well as all the published studies regarding aPDI/antimicrobials combined treatment, and hypotheses regarding the potential mechanisms underlying this synergistic impact have been deeply analysed and thoroughly reviewed in the latest review by Wozniak et al. [80].

\section{Conclusion}

This review provides unquestionable evidence for high bactericidal efficacy of light based approaches to be succsessfully employed when fighting against the most threatening microbes - ESKAPE pathogens. It has been evidenced both with in vitro (planktonic and biofilm cultures) and in vivo studies. Moreover, within the current paper the most potent strategies - nanotechnology, iodide salts and the combination with routinely used antimicrobials - were evidenced to potentiate the bactericidal efficacy of the light based treatments.

\section{Future perspective}

The problem of antibiotic resistance has been perceived by global bodies, including European Commission, ECDC, WHO and antimicrobial resistance (AMR) has become a priority in recent years, illustrated in several important reports [81-83]. However, there still there is no change in the approaches dealing with AMR. The current approaches include: appropriate use of antibiotics; strengthening the regulatory framework on veterinary medicine; recommendation to prudent use of drugs; strengthening infection prevention; strengthening the surveillance system and bringing new antibiotics to patients. All the listed points although important and necessary, will not bring longlasting change in the observed situation. In the case of new antibiotics, unquestionable is the fact that we need new ones, however for those familiar with the rapidness of bacterial evolution, that can be actually observed within days, selection of isolates resistant to new antibiotics is just a matter of time. This is not the case for photoantimicrobials, which act on many targets in bacterial cell. Several bodies of evidence indicated already that the development of resistance in this case is highly unlikely [84-86]. That is why we should focus in the near future on the development and analysis of light-activated multitargeted drugs and bringing the existing ones, for example, MB into clinical practice. Photoantimicrobials and aPDI technology could be easily adapted into main stream clinical practice to reduce AMR level. Although there is a range of PS available, still their action is underappreciated and what is more important research on aPDI is underfunded. Current applications of aPDI concerns local administration of a PS, rather than systemic one, followed by local delivery of light. This secures safety of the technology, however, also limits the possibilities of aPDI applications. Nevertheless, if aPDI could be applied in, for example, wounds decolonization of patients, invasion to the bloodstream and systemic infections could be prevented without application of classical antibiotics. We believe that the future work will be done improving selectivity of PS over host tissue, while sparing the nonselective nature toward microbial species. Ideal PS would be active against both Gram-positive and Gram-negative species, which are known to differently respond to treatment. Another limitation of broader use of photoantimicrobials is lack of mechanistic studies on how PS acts on microbial cells and host cells. Such knowledge is necessary to better design new PS with improved properties, and we believe within next years there will be increased number of studies addressing the problem of molecular basis of aPDI, accordingly as it was done for PDI in cancer cells. Another important issue is light as an indispensable constituent of aPDI action. The way and amount of light is being delivered to the treated place affects aPDI outcome. In recent times, there are several types of light sources available, including lasers and light-emitting diodes for particular applications. Moreover, it would be of great interest to develop a system that allows for the control of light dosimetry at the treated site. The newest aPDI future should be devoted to the development of such an imaging system that would allow therapy to be monitored. From the many in vivo experiments on animal models of infections treatment by aPDI, it is known that often a reinfection occurs. Thus, the system for monitoring both, dosimetry and therapy should be developed. Such technological solution would definitely contribute to broadening the application of aPDI in clinical practice. 
Executive summary

Increasing resistance to clinically applied antimicrobials is noted, specifically among ESKAPE (Enterococcus spp.; Staphylococcus aureus; Klebsiella spp.; Acinetobacter baumannii; Pseudomonas aeruginosa and Enterobacter spp.) pathogens. Antimicrobial photodynamic inactivation (aPDI) constitutes a very good option for clinical application in the treatment of local infections caused by multidrug-resistant pathogens.

In the presented review, we evidenced the newest proofs for:

aPDI against ESKAPE pathogens

- Enterococcus spp. (effective photoinactivation of Enterococcus spp., including vancomycin-resistant E. faecium strains).

- Staphylococcus aureus (effective photoinactivation of S. aureus, including methicillin-resistant S. aureus strains).

- Klebsiella spp. (effective photoinactivation of $K$. pneumoniae, including extended-spectrum $\beta$-lactamases-producing strains).

- Acinetobacter baumannii (effective photoinactivation of $A$. baumannii, including carbapenem-resistant strains).

- Pseudomonas aeruginosa (effective photoinactivation of $P$. aeruginosa, including multidrug-resistant strains).

- Enterobacter spp. (effective photoinactivation of Enterobacter spp.).

Strategies to potentiate aPDI

- Potentiation of aPDI by nanotechnology.

- Potentiation of aPDI by inorganic salts.

- Potentiation of aPDI by antimicrobials.

Financial \& competing interests disclosure

The work was supported by the National Science Centre (Poland) grant nos. 2015/19/B/NZ7/02487 and 2017/27/B/NZ7/02323. The authors have no other relevant affiliations or financial involvement with any organization or entity with a financial interest in or financial conflict with the subject matter or materials discussed in the manuscript apart from those disclosed.

No writing assistance was utilized in the production of this manuscript.

\section{Open access}

This work is licensed under the Attribution-NonCommercial-NoDerivatives 4.0 Unported License. To view a copy of this license, visit http://creativecommons.org/licenses/by-nc-nd/4.0/

\section{References}

Papers of special note have been highlighted as: $\bullet$ of interest; $\bullet \bullet$ of considerable interest

1. Rice LB. Federal funding for the study of antimicrobial resistance in nosocomial pathogens: no ESKAPE. J. Infect. Dis. 197(8), 1079-1081 (2008).

2. National Nosocomial Infections Surveillance S. National nosocomial infections surveillance (NNIS) system report, data summary from January 1992 through June 2004, issued October 2004. Am. J. Infect. Control. 32(8), 470-485 (2004).

3. Boucher HW, Corey GR. Epidemiology of methicillin-resistant Staphylococcus aureus. Clin. Infect. Dis. 46(Suppl. 5), S344-S349 (2008).

4. Falagas ME, Bliziotis IA. Pandrug-resistant Gram-negative bacteria: the dawn of the post-antibiotic era? Int. J. Antimicrob. Agents 29(6), 630-636 (2007).

5. Chopra I, Schofield C, Everett M et al. Treatment of health-care-associated infections caused by Gram-negative bacteria: a consensus statement. Lancet Infect. Dis. 8(2), 133-139 (2008).

6. Wainwright M. Photodynamic antimicrobial chemotherapy (PACT). J. Antimicrob. Chemother. 42(1), 13-28 (1998).

7. Fisher K, Phillips C. The ecology, epidemiology and virulence of Enterococcus. Microbiology 155(Pt 6), 1749-1757 (2009).

8. Poh CH, Oh HM, Tan AL. Epidemiology and clinical outcome of enterococcal bacteraemia in an acute care hospital. J. Infect. 52(5), 383-386 (2006).

9. Love RM. Enterococcus faecalis - a mechanism for its role in endodontic failure. Int. Endod. J. 34(5), 399-405 (2001).

10. Arias CA, Murray BE. Antibiotic-resistant bugs in the 21st century - a clinical super-challenge. N. Engl. J. Med. 360(5), 439-443 (2009).

11. Liu C, Zhou Y, Wang L et al. Mechanistic aspects of the photodynamic inactivation of vancomycin-resistant Enterococci mediated by 5-aminolevulinic acid and 5-aminolevulinic acid methyl ester. Curr. Microbiol. 70(4), 528-535 (2015).

- Describes mechanistic aspects of antimicrobial photodynamic inactivation (aPDI) toward vancomycin-resistant Enterococci.

12. Borba ASM, Da Silva Pereira SM, Borba MCM et al. Photodynamic therapy with high-power LED mediated by erythrosine eliminates Enterococcus faecalis in planktonic forms. Photodiagnosis Photodyn. Ther. 19, 348-351 (2017). 
13. Cieplik F, Spath A, Regensburger J et al. Photodynamic biofilm inactivation by SAPYR - an exclusive singlet oxygen photosensitizer. Free Radic. Biol. Med. 65, 477-487 (2013).

- Describes novel, highly active photosensitizer.

14. Diogo P, Fernandes C, Caramelo F et al. Antimicrobial photodynamic therapy against endodontic Enterococcus faecalis and Candida albicans mono and mixed biofilms in the presence of photosensitizers: a comparative study with classical endodontic irrigants. Front. Microbiol. 8, 498 (2017).

15. López-Jimènez L, Fuste E, Martinez-Garriga B, Arnabat-Dominguez J, Vinuesa T, Vinas M. Effects of photodynamic therapy on Enterococcus faecalis biofilms. Lasers Med. Sci. 30(5), 1519-1526 (2015).

16. Cieplik F, Pummer A, Leibl C et al. Photodynamic inactivation of root canal bacteria by light activation through human dental hard and simulated surrounding tissue. Front. Microbiol. 7, 929 (2016).

17. Tennert C, Feldmann K, Haamann E et al. Effect of photodynamic therapy (PDT) on Enterococcus faecalis biofilm in experimental primary and secondary endodontic infections. BMC Oral Health 14, 132 (2014).

18. Noskin GA, Rubin RJ, Schentag JJ et al. National trends in Staphylococcus aureus infection rates: impact on economic burden and mortality over a 6-year period (1998-2003). Clin. Infect. Dis. 45(9), 1132-1140 (2007).

19. Miller LG, Diep BA. Clinical practice: colonization, fomites, and virulence: rethinking the pathogenesis of community-associated methicillin-resistant Staphylococcus aureus infection. Clin. Infect. Dis. 46(5), 752-760 (2008).

20. Sakoulas G, Moellering RC Jr. Increasing antibiotic resistance among methicillin-resistant Staphylococcus aureus strains. Clin. Infect. Dis. 46(Suppl. 5), S360-S367 (2008).

21. Gardete S, Tomasz A. Mechanisms of vancomycin resistance in Staphylococcus aureus J. Clin. Invest. 124(7), 2836-2840 (2014).

22. Maisch T, Eichner A, Spath A et al. Fast and effective photodynamic inactivation of multiresistant bacteria by cationic riboflavin derivatives. PLoS ONE 9(12), e111792 (2014).

23. Vecchio D, Bhayana B, Huang L, Carrasco E, Evans CL, Hamblin MR. Structure-function relationships of Nile blue (EtNBS) derivatives as antimicrobial photosensitizers. Eur. J. Med. Chem. 75, 479-491 (2014).

24. Urrutia MN, Alovero FL, Ortiz CS. New azine compounds as photoantimicrobial agents against Staphylococcus aureus.. Dyes Pigments $116,27-35$ (2015).

25. Agazzi ML, Ballatore MB, Reynoso E, Quiroga ED, Durantini EN. Synthesis, spectroscopic properties and photodynamic activity of two cationic BODIPY derivatives with application in the photoinactivation of microorganisms. Eur. J. Med. Chem. 126, 110-121 (2017).

26. Biel MA, Pedigo L, Gibbs A, Loebel N. Photodynamic therapy of antibiotic-resistant biofilms in a maxillary sinus model. Int. Forum Allergy Rhinol. 3(6), 468-473 (2013).

27. Rosa LP, Da Silva FC, Nader SA, Meira GA, Viana MS. Antimicrobial photodynamic inactivation of Staphylococcus aureus biofilms in bone specimens using methylene blue, toluidine blue ortho and malachite green: an in vitro study. Arch. Oral Biol. 60(5), 675-680 (2015).

28. Grinholc M, Nakonieczna J, Fila G et al. Antimicrobial photodynamic therapy with fulleropyrrolidine: photoinactivation mechanism of Staphylococcus aureus, in vitro and in vivo studies. Appl. Microbiol. Biotechnol. 99(9), 4031-4043 (2015).

29. Morimoto K, Ozawa T, Awazu K et al. Photodynamic therapy using systemic administration of 5-aminolevulinic acid and a 410-nm wavelength light-emitting diode for methicillin-resistant Staphylococcus aureus-infected ulcers in mice. PLoS ONE 9(8), e105173 (2014)

30. Edwards L, Turner D, Champion C et al. Photoactivated 2,3-distyrylindoles kill multi-drug resistant bacteria. Bioorg. Med. Chem. Lett. 28(10), 1879-1886 (2018).

31. Carpenter BL, Situ X, Scholle F, Bartelmess J, Weare WW, Ghiladi RA. Antiviral, antifungal and antibacterial activities of a BODIPY-based photosensitizer. Molecules 20(6), 10604-10621 (2015).

32. Misba L, Zaidi S, Khan AU. A comparison of antibacterial and antibiofilm efficacy of phenothiazinium dyes between Gram positive and Gram negative bacterial biofilm. Photodiagnosis Photodyn. Ther. 18, 24-33 (2017).

33. Huang L, Szewczyk G, Sarna T, Hamblin MR. Potassium iodide potentiates broad-spectrum antimicrobial photodynamic inactivation using photofrin. ACS Infect. Dis. 3(4), 320-328 (2017).

-• Describes one of the most potent strategies leading to enhanced bactericidal efficacy of aPDI, in other words, employment of potassium iodide.

34. Liu C, Zhou Y, Wang L et al. Photodynamic inactivation of Klebsiella pneumoniae biofilms and planktonic cells by 5-aminolevulinic acid and 5-aminolevulinic acid methyl ester. Lasers Med. Sci. 31(3), 557-565 (2016).

35. Miretti M, Clementi R, Tempesti TC, Baumgartner MT. Photodynamic inactivation of multiresistant bacteria (KPC) using zinc(II)phthalocyanines. Bioorg. Med. Chem. Lett. 27(18), 4341-4344 (2017).

36. Xu F, Li Y, Ahmad J, Wang Y, Scott DE, Vostal JG. Vitamin K5 is an efficient photosensitizer for ultraviolet A light inactivation of bacteria. FEMS Microbiol. Lett. 365(4), (2018).

37. Grego KF, Carvalho MPN, Cunha MPV et al. Antimicrobial photodynamic therapy for infectious stomatitis in snakes: clinical views and microbiological findings. Photodiagnosis Photodyn. Ther. 20, 196-200 (2017). 
38. Santajit S, Indrawattana N. Mechanisms of antimicrobial resistance in ESKAPE pathogens. Biomed. Res. Int. 2016, 2475067 (2016).

39. Howard A, O'Donoghue M, Feeney A, Sleator RD. Acinetobacter baumannii: an emerging opportunistic pathogen. Virulence 3(3), 243-250 (2012).

40. Navidinia M. The clinical importance of emerging ESKAPE pathogens in nosocomial infections. J. Paramed. Sci. 7, 2008-4978 (2016).

41. Huang L, Krayer M, Roubil JG et al. Stable synthetic mono-substituted cationic bacteriochlorins mediate selective broad-spectrum photoinactivation of drug-resistant pathogens at nanomolar concentrations. J. Photochem. Photobiol. B 141, 119-127 (2014).

42. Halstead FD, Thwaite JE, Burt R et al. The antibacterial activity of blue light against nosocomial wound pathogens growing planktonically and as mature biofilms. Appl. Environ. Microbiol. 82(13), 4006-4016 (2016).

- Describes antibacterial activity of antimicrobial blue light (aBL) against numerous human pathogens growing in mature biofilms.

43. Almeida J, Tome JP, Neves MG et al. Photodynamic inactivation of multidrug-resistant bacteria in hospital wastewaters: influence of residual antibiotics. Photochem. Photobiol. Sci. 13(4), 626-633 (2014).

44. Yuan Y, Liu ZQ, Jin $\mathrm{H}$ et al. Photodynamic antimicrobial chemotherapy with the novel amino acid-porphyrin conjugate 4I: in vitro and in vivo studies. PLoS ONE 12(5), e0176529 (2017).

45. Wang $\mathrm{Y}, \mathrm{Wu} \mathrm{X}, \mathrm{Chen} \mathrm{J}$ et al. Antimicrobial blue light inactivation of gram-negative pathogens in biofilms: in vitro and in vivo studies. J. Infect. Dis. 213(9), 1380-1387 (2016).

46. Gaynes R, Edwards JR, National Nosocomial Infections Surveillance System. Overview of nosocomial infections caused by gram-negative bacilli. Clin. Infect. Dis. 41(6), 848-854 (2005).

47. Zhang Y, Chen XL, Huang AW et al. Mortality attributable to carbapenem-resistant Pseudomonas aeruginosa bacteremia: a meta-analysis of cohort studies. Emerg. Microbes Infect. 5, e27 (2016).

48. Boucher HW, Talbot GH, Bradley JS et al. Bad bugs, no drugs: no ESKAPE! An update from the infectious diseases society of america. Clin. Infect. Dis. 48(1), 1-12 (2009).

49. Beirao S, Fernandes S, Coelho J et al. Photodynamic inactivation of bacterial and yeast biofilms with a cationic porphyrin. Photochem. Photobiol. 90(6), 1387-1396 (2014).

50. Orlandi VT, Rybtke M, Caruso E, Banfi S, Tolker-Nielsen T, Barbieri P. Antimicrobial and anti-biofilm effect of a novel BODIPY photosensitizer against Pseudomonas aeruginosa PAO1. Biofouling 30(8), 883-891 (2014).

51. Fila G, Kasimova K, Arenas Y et al. Murine model imitating chronic wound infections for evaluation of antimicrobial photodynamic therapy efficacy. Front. Microbiol. 7, 1258 (2016).

52. Amin RM, Bhayana B, Hamblin MR, Dai T. Antimicrobial blue light inactivation of Pseudomonas aeruginosa by photo-excitation of endogenous porphyrins: in vitro and in vivo studies. Lasers Surg. Med. 48(5), 562-568 (2016).

-• Describes complex studies concerning aBL treatment of $P$. aeruginosa including both in vitro and in vivo models.

53. Fila G, Krychowiak M, Rychlowski M, Bielawski KP, Grinholc M. Antimicrobial blue light photoinactivation of Pseudomonas aeruginosa: quorum sensing signaling molecules, biofilm formation and pathogenicity. J. Biophotonics 11 (11), e201800079 (2018).

- Describes the use of aBL toward $P$, aeruginosa, and moreover, its impact on reduced bacterial pathogenicity.

54. Fila G, Kawiak A, Grinholc MS. Blue light treatment of Pseudomonas aeruginosa: Strong bactericidal activity, synergism with antibiotics and inactivation of virulence factors. Virulence 8(6), 938-958 (2017).

55. Katayama B, Ozawa T, Morimoto K et al. Enhanced sterilization and healing of cutaneous pseudomonas infection using 5-aminolevulinic acid as a photosensitizer with 410-nm LED light. J. Dermatol. Sci. 90(3), 323-331 (2018).

56. Wen X, Zhang X, Szewczyk G et al. Potassium iodide potentiates antimicrobial photodynamic inactivation mediated by rose bengal in in vitro and in vivo studies. Antimicrob. Agents Chemother. 61(7), pii:e00467-17 (2017).

57. Deshpande LM, Jones RN, Fritsche TR, Sader HS. Occurrence and characterization of carbapenemase-producing Enterobacteriaceae: report from the SENTRY antimicrobial surveillance program (2000-2004). Microb. Drug Resist. 12(4), 223-230 (2006).

58. Lin YC, Chen TL, Ju HL et al. Clinical characteristics and risk factors for attributable mortality in Enterobacter cloacae bacteremia. J. Microbiol. Immunol. Infect. 39(1), 67-72 (2006).

59. Khan S, Khan SN, Meena R, Dar AM, Pal R, Khan AU. Photoinactivation of multidrug resistant bacteria by monomeric methylene blue conjugated gold nanoparticles. J. Photochem. Photobiol. B 174, 150-161 (2017).

60. Pereira De Lima Carvalho D, Guerra Pinto J, Di Paula Costa Sorge C, Rodrigues Benedito FR, Khouri S, Ferreira Strixino J. Study of photodynamic therapy in the control of isolated microorganisms from infected wounds - an in vitro study. Lasers Med. Sci. 29(1), 113-120 (2014).

61. Rossoni RD, Junqueira JC, Santos EL, Costa AC, Jorge AO. Comparison of the efficacy of Rose Bengal and erythrosin in photodynamic therapy against Enterobacteriaceae.. Lasers Med. Sci. 25(4), 581-586 (2010).

62. Halstead FD, Thwaite JE, Burt R et al. Antibacterial activity of blue light against nosocomial wound pathogens growing planktonically and as mature biofilms. Appl. Environ. Microbiol. 82(13), 4006-4016 (2016).

63. Tawfik AA, Alsharnoubi J, Morsy M. Photodynamic antibacterial enhanced effect of methylene blue-gold nanoparticles conjugate on Staphylococcal aureus isolated from impetigo lesions in vitro study. Photodiagnosis Photodyn. Ther. 12(2), 215-220 (2015). 
64. Darabpour E, Kashef N, Mashayekhan S. Chitosan nanoparticles enhance the efficiency of methylene blue-mediated antimicrobial photodynamic inactivation of bacterial biofilms: an in vitro study. Photodiagnosis Photodyn. Ther. 14, 211-217 (2016).

65. Misba L, Kulshrestha S, Khan AU. Antibiofilm action of a toluidine blue O-silver nanoparticle conjugate on Streptococcus mutans: a mechanism of type I photodynamic therapy. Biofouling 32(3), 313-328 (2016).

66. Sherwani MA, Tufail S, Khan AA, Owais M. Gold nanoparticle-photosensitizer conjugate based photodynamic inactivation of biofilm producing cells: potential for treatment of C. albicans infection in BALB/c mice. PLoS ONE 10(7), e0131684 (2015).

67. Sadasivam M, Avci P, Gupta GK et al. Self-assembled liposomal nanoparticles in photodynamic therapy. Eur. J. Nanomed. 5(3), doi:10.1515/ejnm-2013-0010 (2013).

68. Chen RJ, Chen PC, Prasannan A et al. Formation of gold decorated porphyrin nanoparticles and evaluation of their photothermal and photodynamic activity. Mater. Sci. Eng. C Mater. Biol. Appl. 63, 678-685 (2016).

69. Nakonieczna J, Rapacka-Zdonczyk A, Kawiak A, Bielawski KP, Grinholc M. Sub-lethal photodynamic inactivation renders Staphylococcus aureus susceptible to silver nanoparticles. Photochem. Photobiol. Sci. 12(9), 1622-1627 (2013).

70. Huang YY, Sharma SK, Dai T et al. Can nanotechnology potentiate photodynamic therapy? Nanotechnol. Rev. 1(2), 111-146 (2012).

71. Shrestha A, Kishen A. Antibacterial efficacy of photosensitizer functionalized biopolymeric nanoparticles in the presence of tissue inhibitors in root canal. J. Endod. 40(4), 566-570 (2014).

72. Chen CP, Chen CT, Tsai T. Chitosan nanoparticles for antimicrobial photodynamic inactivation: characterization and in vitro investigation. Photochem. Photobiol. 88(3), 570-576 (2012).

73. Dai T, Tanaka M, Huang YY, Hamblin MR. Chitosan preparations for wounds and burns: antimicrobial and wound-healing effects. Expert. Rev. Anti. Infect. Ther. 9(7), 857-879 (2011).

74. Darabpour E, Kashef N, Amini SM, Kharrazi S, Djavid GE. Fast and effective photodynamic inactivation of 4-day-old biofilm of methicillin-resistant Staphylococcus aureus using methylene blue-conjugated gold nanoparticles. J. Drug Deliv. Sci. Technol. 37, 134-140 (2017).

75. Vecchio D, Gupta A, Huang L et al. Bacterial photodynamic inactivation mediated by methylene blue and red light is enhanced by synergistic effect of potassium iodide. Antimicrob. Agents Chemother. 59(9), 5203-5212 (2015).

76. Huang L, St Denis TG, Xuan Y et al. Paradoxical potentiation of methylene blue-mediated antimicrobial photodynamic inactivation by sodium azide: role of ambient oxygen and azide radicals. Free Radic. Biol. Med. 53(11), 2062-2071 (2012).

77. St Denis TG, Vecchio D, Zadlo A et al. Thiocyanate potentiates antimicrobial photodynamic therapy: in situ generation of the sulfur trioxide radical anion by singlet oxygen. Free Radic. Biol. Med. 65, 800-810 (2013).

78. Zhang Y, Dai T, Wang M, Vecchio D, Chiang LY, Hamblin MR. Potentiation of antimicrobial photodynamic inactivation mediated by a cationic fullerene by added iodide: in vitro and in vivo studies. Nanomedicine (Lond.) 10(4), 603-614 (2015).

79. Freire F, Ferraresi C, Jorge AO, Hamblin MR. Photodynamic therapy of oral Candida infection in a mouse model. J. Photochem. Photobiol. B 159, 161-168 (2016).

80. Wozniak A, Grinholc M. Combined antimicrobial activity of photodynamic inactivation and antimicrobials-state of the art. Front. Microbiol. 9, 930 (2018).

-• Reviews current knowledge concerning one of the most potent strategies leading to improved aPDI efficacy, in other words, antimicrobials.

81. European Commission. Progress report on the action plan against the rising threats from antimicrobial resistance. (2015). https://ec.europa.eu/health/sites/health/files/antimicrobial_resistance/docs/2015_amr_progress_report_en.pdf

82. ECDC. Annual epidemiological report. Reporting on 2010 surveillance data and 2011 epidemic intelligence data. Surveillance Report. 2012).

83. WHO. Antimicrobial resistance. Global Report on Surveillance. 2014).

84. Giuliani F, Martinelli M, Cocchi A, Arbia D, Fantetti L, Roncucci G. In vitro resistance selection studies of RLP068/Cl, a new Zn(II) phthalocyanine suitable for antimicrobial photodynamic therapy. Antimicrob. Agents Chemother. 54(2), 637-642 (2010).

85. Tavares A, Carvalho CM, Faustino MA et al. Antimicrobial photodynamic therapy: study of bacterial recovery viability and potential development of resistance after treatment. Mar. Drugs 8(1), 91-105 (2010).

86. Wainwright M, Maisch T, Nonell S et al. Photoantimicrobials - are we afraid of the light? Lancet Infect. Dis. 17(2), e49-e55 (2017).

87. De Annunzio SR, De Freitas LM, Blanco AL et al. Susceptibility of Enterococcus faecalis and Propionibacterium acnes to antimicrobial photodynamic therapy. J. Photochem. Photobiol. B 178, 545-550 (2018).

88. Pileggi G, Wataha JC, Girard M et al. Blue light-mediated inactivation of Enterococcus faecalis in vitro. Photodiagnosis Photodyn. Ther. 10(2), 134-140 (2013).

89. Beltes C, Sakkas H, Economides N, Papadopoulou C. Antimicrobial photodynamic therapy using Indocyanine green and near-infrared diode laser in reducing Entrerococcus faecalis. Photodiagnosis Photodyn. Ther. 17, 5-8 (2017).

90. Kashef N, Borghei YS, Djavid GE. Photodynamic effect of hypericin on the microorganisms and primary human fibroblasts. Photodiagnosis Photodyn. Ther. 10(2), 150-155 (2013). 
91. Kumar A, Ghate V, Kim MJ, Zhou W, Khoo GH, Yuk HG. Kinetics of bacterial inactivation by $405 \mathrm{~nm}$ and $520 \mathrm{~nm}$ light emitting diodes and the role of endogenous coproporphyrin on bacterial susceptibility. J. Photochem. Photobiol. B 149, 37-44 (2015).

92. Rapacka-Zdonczyk A, Larsen AR, Empel J, Patel A, Grinholc M. Association between susceptibility to photodynamic oxidation and the genetic background of Staphylococcus aureus. Eur. J. Clin. Microbiol. Infect. Dis. 33(4), 577-586 (2014).

93. Kossakowska-Zwierucho M, Kazmierkiewicz R, Bielawski KP, Nakonieczna J. Factors determining Staphylococcus aureus susceptibility to photoantimicrobial chemotherapy: RsbU activity, staphyloxanthin level, and membrane fluidity. Front. Microbiol. 7, 1141 (2016).

94. Bartolomeu M, Rocha S, Cunha A, Neves MG, Faustino MA, Almeida A. Effect of photodynamic therapy on the virulence factors of Staphylococcus aureus. Front. Microbiol. 7, 267 (2016).

95. Fekrazad R, Zare H, Vand SM. Photodynamic therapy effect on cell growth inhibition induced by Radachlorin and toluidine blue O on Staphylococcus aureus and Escherichia coli: an in vitro study. Photodiagnosis Photodyn. Ther. 15, 213-217 (2016).

96. Vecchio D, Dai T, Huang L, Fantetti L, Roncucci G, Hamblin MR. Antimicrobial photodynamic therapy with RLP068 kills methicillin-resistant Staphylococcus aureus and improves wound healing in a mouse model of infected skin abrasion PDT with RLP068/Cl in infected mouse skin abrasion. J. Biophotonics 6(9), 733-742 (2013).

97. Ke MR, Eastel JM, Ngai KL et al. Photodynamic inactivation of bacteria and viruses using two monosubstituted zinc(II) phthalocyanines. Eur. J. Med. Chem. 84, 278-283 (2014).

98. Ribeiro AP, Pavarina AC, Dovigo LN et al. Phototoxic effect of curcumin on methicillin-resistant Staphylococcus aureus and L929 fibroblasts. Lasers Med. Sci. 28(2), 391-398 (2013).

99. Garcia I, Ballesta S, Gilaberte Y, Rezusta A, Pascual A. Antimicrobial photodynamic activity of hypericin against methicillin-susceptible and resistant Staphylococcus aureus biofilms. Future Microbiol. 10(3), 347-356 (2015).

100. Taraszkiewicz A, Grinholc M, Bielawski KP, Kawiak A, Nakonieczna J. Imidazoacridinone derivatives as efficient sensitizers in photoantimicrobial chemotherapy. Appl. Environ. Microbiol. 79(12), 3692-3702 (2013).

101. Ballatore MB, Spesia MB, Milanesio ME, Durantini EN. Synthesis, spectroscopic properties and photodynamic activity of porphyrin-fullerene C60 dyads with application in the photodynamic inactivation of Staphylococcus aureus. Eur. J. Med. Chem. 83, 685-694 (2014).

102. Fekrazad R, Zare H, Mohammadi Sepahvand S, Morsali P. The effect of antimicrobial photodynamic therapy with radachlorin(R) on Staphylococcus aureus and Escherichia coli: an in vitro study. J. Lasers Med. Sci. 5(2), 82-85 (2014).

103. Arenas Y, Monro S, Shi G, Mandel A, McFarland S, Lilge L. Photodynamic inactivation of Staphylococcus aureus and methicillin-resistant Staphylococcus aureus with Ru(II)-based type I/type II photosensitizers. Photodiagnosis Photodyn. Ther. 10(4), 615-625 (2013).

104. Wang Y, Zhou Q, Wang Y et al. In vitro photodynamic inactivation effects of Ru(II) complexes on clinical methicillin-resistant Staphylococcus aureus planktonic and biofilm cultures. Photochem. Photobiol. 91(1), 124-133 (2015).

105. Carpenter BL, Scholle F, Sadeghifar H et al. Synthesis, characterization, and antimicrobial efficacy of photomicrobicidal cellulose paper. Biomacromolecules 16(8), 2482-2492 (2015).

106. Zhang Y, Zhu Y, Gupta A et al. Antimicrobial blue light therapy for multidrug-resistant Acinetobacter baumannii infection in a mouse burn model: implications for prophylaxis and treatment of combat-related wound infections. J. Infect. Dis. 209(12), 1963-1971 (2014).

107. Rineh A, Bremner JB, Hamblin MR, Ball AR, Tegos GP, Kelso MJ. Attaching NorA efflux pump inhibitors to methylene blue enhances antimicrobial photodynamic inactivation of Escherichia coli and Acinetobacter baumannii in vitro and in vivo. Bioorg. Med. Chem. Lett. 28(16), 2736-2740 (2018).

108. Dai T, Garcia B, Murray CK, Vrahas MS, Hamblin MR. UVC light prophylaxis for cutaneous wound infections in mice. Antimicrob. Agents Chemother. 56(7), 3841-3848 (2012).

109. Hsieh CM, Huang YH, Chen CP, Hsieh BC, Tsai T. 5-Aminolevulinic acid induced photodynamic inactivation on Staphylococcus aureus and Pseudomonas aeruginosa. J. Food Drug Anal. 22(3), 350-355 (2014).

110. Orlandi VT, Bolognese F, Chiodaroli L, Tolker-Nielsen T, Barbieri P. Pigments influence the tolerance of Pseudomonas aeruginosa PAO1 to photodynamically induced oxidative stress. Microbiology 161(12), 2298-2309 (2015).

111. Pucelik B, Paczynski R, Dubin G, Pereira MM, Arnaut LG, Dabrowski JM. Properties of halogenated and sulfonated porphyrins relevant for the selection of photosensitizers in anticancer and antimicrobial therapies. PLoS ONE 12(10), e0185984 (2017).

112. Mamone L, Ferreyra DD, Gandara L et al. Photodynamic inactivation of planktonic and biofilm growing bacteria mediated by a meso-substituted porphyrin bearing four basic amino groups. J. Photochem. Photobiol. B 161, 222-229 (2016).

113. Forte Giacobone AF, Ruiz Gale MF, Hogert EN, Oppezzo OJ. A possible phenomenon of persistence in Pseudomonas aeruginosa treated with methylene blue and red light. Photochem. Photobiol. 92(5), 702-707 (2016).

114. Shih MH, Huang FC. Repetitive methylene blue-mediated photoantimicrobial chemotherapy changes the susceptibility and expression of the outer membrane proteins of Pseudomonas aeruginosa. Photodiagnosis Photodyn. Ther. 10(4), 664-671 (2013).

115. Mantareva V, Kussovski V, Durmus M, Borisova E, Angelov I. Photodynamic inactivation of pathogenic species Pseudomonas aeruginosa and Candida albicans with lutetium (III) acetate phthalocyanines and specific light irradiation. Lasers Med. Sci. 31(8), 1591-1598 (2016). 
116. Muehler D, Sommer K, Wennige S et al. Light-activated phenalen-1-one bactericides: efficacy, toxicity and mechanism compared with benzalkonium chloride. Future Microbiol. 12, 1297-1310 (2017).

117. Donauerova A, Bujdak J, Smolinska M, Bujdakova H. Photophysical and antibacterial properties of complex systems based on smectite, a cationic surfactant and methylene blue. J. Photochem. Photobiol. B 151, 135-141 (2015).

118. Rosa LP, Da Silva FC, Viana MS, Meira GA. In vitro effectiveness of 455-nm blue LED to reduce the load of Staphylococcus aureus and Candida albicans biofilms in compact bone tissue. Lasers Med. Sci. 31(1), 27-32 (2016).

119. Giannelli M, Landini G, Materassi F et al. Effects of photodynamic laser and violet-blue led irradiation on Staphylococcus aureus biofilm and Escherichia coli lipopolysaccharide attached to moderately rough titanium surface: in vitro study. Lasers Med. Sci. 32(4), 857-864 (2017).

120. Vassena C, Fenu S, Giuliani F et al. Photodynamic antibacterial and antibiofilm activity of RLP068/Cl against Staphylococcus aureus and Pseudomonas aeruginosa forming biofilms on prosthetic material. Int. J. Antimicrob. Agents 44(1), 47-55 (2014).

121. Rodig T, Endres S, Konietschke F, Zimmermann O, Sydow HG, Wiegand A. Effect of fiber insertion depth on antibacterial efficacy of photodynamic therapy against Enterococcus faecalis in rootcanals. Clin. Oral Investig. 21(5), 1753-1759 (2017).

122. Zhu H, Kochevar IE, Behlau I et al. Antimicrobial blue light therapy for infectious keratitis: ex vivo and in vivo studies. Invest. Ophthalmol. Vis. Sci. 58(1), 586-593 (2017).

123. Lei X, Liu B, Huang Z, Wu J. A clinical study of photodynamic therapy for chronic skin ulcers in lower limbs infected with Pseudomonas aeruginosa. Arch. Dermatol. Res. 307(1), 49-55 (2015). 
